\title{
The Impact of Debt Levels and Debt Maturity on Inflation *
}

\author{
Faraglia, Elisa $^{\dagger} \quad$ Marcet, Albert ${ }^{\ddagger} \quad$ Oikonomou, Rigas $\S$ \\ Scott, Andrew
}

September 14, 2012

\begin{abstract}
In the context of a sticky price DSGE model subject to government expenditure and preference shocks where governments issue only nominal non-contingent bonds we examine the implications for optimal inflation of changes in the level and average maturity of government debt. We analyse these relationships under two different institutional settings. In one case government pursues optimal monetary and fiscal policy in a coordinated way whereas in the alternative we assume an independent monetary authority that sets interest rates according to a Taylor rule and where the fiscal authority treats bond prices as a given. We identify the main mechanisms through which inflation is affected by debt and debt maturity (a real balance effect and an implicit profit tax) and also study additional channels through which the government achieves fiscal sustainability (tax smoothing, interest rate twisting and endogenous fluctuations in bond prices). In the case of optimal coordinated monetary and fiscal policy we find that the persistence and volatility of inflation depends on the sign, size and maturity structure of government debt. High levels of government debt do lead to higher inflation and longer maturity debt leads to more persistent inflation. However even in the presence of modest price stickiness the role of inflation is minor with the majority of fiscal adjustment achieved through changes in taxes and the primary surplus. However in the case of an independent monetary authority where debt management, monetary policy and fiscal policy are not coordinated then inflation has a much more substantial and more persistent role to play. Inflation is higher, more volatile and more persistent especially in response to preference shocks and plays a major role in achieving fiscal solvency.
\end{abstract}

JEL classification: E52, E62, H21, H63

\footnotetext{
* Marcet is grateful for support from DGES, Monfispol and Excellence Program if Banco de Espana. Faraglia and Scott gratefully acknowledge funding from the ESRC's World Economy and Finance Program. Oikonomou is grateful to HEC Montreal for funding. Thanks to Giorgia Palladini for research assistance. Helpful feedback from Wouter den Haan and Pedro Teles are gratefully acknowledged .

$\dagger$ University of Cambridge and CEPR

${ }^{\ddagger}$ Institut d’Analisi Economica, ICREA UAB, BGSE and CEPR

$\S$ HEC Montreal

『London Business School and CEPR
} 
Keywords: Fiscal Insurance, Fiscal Sustainability, Government Debt, Inflation, Interest Rates, Maturity. 


\section{Introduction}

Rising levels of government debt in the OECD in the wake of the financial crisis of 2007/8 are raising numerous concerns. Most obviously issues of fiscal sustainability are triggering a sovereign debt crisis, notably in the Euro area. Related to this concern is the notion that governments will use inflation in order to achieve fiscal solvency without resorting to distortionary labour taxes. For instance, Aizenman and Marion (2009) calculate that a persistent inflation rate of $5 \%$ will contribute significantly to stabilising US public finances. In contrast the evidence of Giannitsarou and Scott (2007) and Hall and Sargent (2010), using historical data, suggests that inflation has played a relatively minor role in achieving debt sustainability. Much discussion around the link between debt and inflation also includes a focus on the maturity structure of government debt with a widespread belief that the longer is the maturity of government debt the greater the incentive to use inflation. In this paper we examine optimal Ramsey policy for a government that controls labour taxes and inflation in an economy characterised by monopolistic competition and sticky prices. In doing so we follow the work of Schmitt-Grohe and Uribe (2004) and Siu (2004) who show how price adjustment costs limit the ability of inflation to make a substantial contribution to fiscal sustanability and Lustig, Sleet and Yeltekin (2008) who extend this work to consider long maturity bonds and show that governments use inflation more if they can issue long term bonds and that it is optimal to do so.

Our model is outlined in Section 2 and is similar to those of Schmitt-Grohe and Uribe (2004), Siu (2004) and Lustig et al. (2008). It focuses on a government which sets optimal policy under commitment in a monopolistically competitive environment characterised by sticky prices and incomplete bond markets in which governments cannot issue a complete set of contingent claims but instead issue nominal non-state contingent bonds. As in Lustig et al. (2008) we allow the maturity of government debt to be greater than a single period. Using the computational method of Faraglia, Marcet and Scott (2012) enables us to consider much longer maturities (in this case up to 20 periods) than previously analysed although unlike Lustig et al (2008) we do not focus on the composition of debt but simply focus on changes to average maturity. We extend previous work in this area by focusing not just on government expenditure shocks but also allow for preference shifts that bring about fluctuations in consumption that can be considered demand side shocks.

In Section 3 we consider a simplified version of our model with shocks in the first period only. We use this simple environment to identify the key mechanisms through which the government uses inflation to stabilise debt - a real liability effect and an implicit profit tax - and examine how these channels are affected by the level, sign and maturity of government debt. In Section 4 we then consider using full stochastic simulations the properties of our model and the properties of inflation using both long and short run samples. We find that price stickiness dominates the desire to use inflation to stabilise debt and so inflation shows only very modest changes in response to expenditure shocks and only for the duration of bond maturity. Longer bonds do lead to stronger and more persistent inflation but the role is still minor. In the case of preference shocks the inflation impact is larger but the advantage of using long bonds is less.

In Section 5 we consider an alternative and more empiricaly relevant institutional setting in which fiscal policy is set optimally but an independent monetary authority sets interest rates according to a Taylor rule and bond prices are taken as given by the fiscal authority. This alternative institutional structure has substantial effects on policy and leads to far more substantial fluctuations in inflation which are considerably more persistent 
than under optimal coordinated policy. The impact is especially noticeable in response to preference shocks. These conclusions are reinforced in Section 6 where we investigate the role of inflation and interest rates in achieving fiscal sustainability. Under the jointly optimal (coordinated) policy and in response to both shocks inflation fulfills a relatively modest role with changes in taxes and the primary position being the most important variable. When monetary and fiscal policies are conducted by separate (uncoordinated) authorities inflation becomes essential in making the debt level manageable. A final section concludes.

\section{Model}

\section{$2.1 \quad$ Agents}

\section{Preferences}

Ours is an infinite horizon economy populated by a large number of identical households with preferences defined by:

$$
E_{0} \sum_{t=0}^{\infty} \beta^{t} u\left(c_{t}, \xi_{t}\right)+v\left(h_{t}\right)
$$

where $c_{t}$ denotes consumption, $h_{t}$ hours and $\beta$ is the subjective discount factor. The term $\xi_{t}$ is a preference shock which shifts the utility of consumption. For each value of $\xi_{t}$, utility $u\left(c_{t}, \xi_{t}\right)$ is assumed increasing and concave in consumption.

\section{Firms}

In every period $t$ the economy produces a final good $Y_{t}$ which is a Dixit-Stigltiz composite of a continuum of differentiated intermediate products. Each household is a monopolistic producer of one of these intermediate products which are produced with a linear technology $y_{t}=h_{t}$. Demand for the intermediate good is given by $Y_{t} d\left(p_{t}\right)$, where $p_{t}$ is the relative price of the intermediate good in terms of the composite final good. The demand function $d$ satisfies additional assumptions that guarantee the existence of a symmetric equilibrium namely $d(1)=1$ and $d^{\prime}(1)<-1$.

Let $P_{i, t}$ denote the price of a generic intermediate product $i$ and introduce sticky prices through adjustment costs given by $\frac{\theta}{2}\left(\frac{P_{i, t}}{P_{i, t-1}}-1\right)^{2}$ where the parameter $\theta$ governs the degree of price stickiness. The higher $\theta$ is the higher the resource cost of adjusting prices and when $\theta=0$ prices are fully flexible.

Intermediate good producers seek to maximize:

$$
E_{t} \sum_{j=0}^{\infty} \beta^{j} \frac{u_{c}\left(c_{t+j}, \xi_{t+j}\right)}{u_{c}\left(c_{t}, \xi_{t}\right)}\left[\frac{P_{i, t+j}}{P_{t+j}} Y_{t+j} d\left(\frac{P_{i, t+j}}{P_{t+j}}\right)-w_{t+j} h_{i, t+j}-\frac{\theta}{2}\left(\frac{P_{i, t+j}}{P_{i, t+j-1}}-1\right)^{2}\right]
$$

subject to the constraint $h_{i, t+j}=Y_{t+j} d\left(\frac{P_{i, t+j}}{P_{t+j}}\right)$. The stochastic discount factor $\beta^{j} \frac{u_{c}\left(c_{t+j}, \xi_{t+j}\right)}{u_{c}\left(c_{t}, \xi_{t}\right)}$ is used to evaluate future profits and $w_{t+j}$ is the wage rate in the competitive labor market which firms hire from. The firm's first order condition with respect to $P_{t}$ is given by:

$$
\begin{aligned}
\frac{1}{P_{t}} Y_{t} d\left(\frac{P_{i, t}}{P_{t}}\right) & +\frac{P_{i, t}}{P_{t}^{2}} Y_{t} d^{\prime}\left(\frac{P_{i, t}}{P_{t}}\right)-w_{t} Y_{t} d^{\prime}\left(\frac{P_{i, t}}{P_{t}}\right) \frac{1}{P_{t}}-\theta\left(\frac{P_{i, t}}{P_{i, t-1}}-1\right) \frac{1}{P_{i, t-1}} \\
& +\beta E_{t} \frac{u_{c}(t+1)}{u_{c}(t)} \theta\left(\frac{P_{i, t+1}}{P_{i, t}}-1\right) \frac{P_{i, t+1}}{P_{i, t}^{2}}=0
\end{aligned}
$$


This equation forms the "Phillips curve" describing the inflation output trade-off at the heart of our model. Letting $d^{\prime}(1)=\eta$ and imposing a symmetric equilibrium such that all firms set the same price gives:

$$
\frac{Y_{t} \eta}{\theta}\left(\frac{(1+\eta)}{\eta}-w_{t}\right)-\left(\pi_{t}-1\right) \pi_{t}+\beta E_{t} \frac{u_{c}\left(c_{t+1}, \xi_{t+1}\right)}{u_{c}\left(c_{t}, \xi_{t}\right)}\left(\pi_{t+1}-1\right) \pi_{t+1}=0
$$

where $\pi_{t}=\frac{P_{t}}{P_{t-1}}$ denotes gross inflation.

\section{Government and Markets}

The government engages in two activities - it levies taxes $\tau_{t}$ on households' labor income and trades with households in bond markets to finance a spending process $\left\{g_{t}\right\}_{0}^{\infty}$. We assume only one type of asset, a nominal bond of maturity $N$. We denote by $B_{t}^{N}$ the quantity of this bond issued in period $t$ and its price by $q_{t}^{N}$. We assume each period the government buys back the entire stock of debt issued in the previous period. The government budget constraint is therefore :

$$
q_{t}^{N} B_{t}^{N}=q_{t}^{N-1} B_{t-1}^{N}+P_{t}\left(g_{t}-\tau_{t} w_{t} h_{t}\right)
$$

\subsection{The Ramsey Problem}

To solve for optimal policy we substitute out from the planner's constraint for taxes and bond prices. In a competitive equilibrium $\left(1-\tau_{t}\right) w_{t}=-\frac{v_{h}\left(h_{t}\right)}{u_{c}\left(c_{t}, \xi_{t}\right)}$ and $q_{t}^{N}=\beta^{N} E_{t} \frac{u_{c}\left(c_{t+N}, \xi_{t+N}\right)}{u_{c}\left(c_{t}, \xi_{t}\right) \Pi_{j=1}^{N} \pi_{t+j}}$ with $q_{t}^{0}=1$. Using these substitutions the government budget constraint becomes:

$$
\begin{aligned}
\beta^{N} E_{t} \frac{u_{c}\left(c_{t+N}, \xi_{t+N}\right)}{u_{c}\left(c_{t}, \xi_{t}\right) \Pi_{j=1}^{N} \pi_{t+j}} B_{t}^{N} & =\beta^{N-1} E_{t} \frac{u_{c}\left(c_{t+N-1}, \xi_{t+N-1}\right)}{u_{c}\left(c_{t}, \xi_{t}\right) \Pi_{j=1}^{N-1} \pi_{t+j}} B_{t-1}^{N} \\
& +P_{t}\left(g_{t}-\left(1+\frac{v_{h}\left(h_{t}\right)}{u_{c}\left(c_{t}, \xi_{t}\right) w_{t}}\right) w_{t} h_{t}\right)
\end{aligned}
$$

Multiplying by the marginal utility of consumption in period $t$, dividing by $P_{t}$ and letting $b_{t}^{N}=\frac{B_{t}^{N}}{P_{t}}$ denote the real debt level, gives:

$$
\begin{aligned}
\beta^{N} E_{t} \frac{u_{c}\left(c_{t+N}, \xi_{t+N}\right)}{\prod_{j=1}^{N} \pi_{t+j}} b_{t}^{N} & =\beta^{N-1} E_{t} \frac{u_{c}\left(c_{t+N-1}, \xi_{t+N-1}\right)}{\prod_{j=1}^{N-1} \pi_{t+j}} \frac{b_{t-1}^{N}}{\pi_{t}} \\
& +u_{c}\left(c_{t}, \xi_{t}\right)\left(g_{t}-\left(1+\frac{v_{h}\left(h_{t}\right)}{u_{c}\left(c_{t}, \xi_{t}\right) w_{t}}\right) w_{t} h_{t}\right)
\end{aligned}
$$

In a competitive equilibrium aggregate output equals hours worked i.e. $Y_{t}=h_{t}$ so our Phillips curve becomes:

$$
\left(\pi_{t}-1\right) \pi_{t}=\frac{h_{t} \eta}{\theta}\left(\frac{(1+\eta)}{\eta}-w_{t}\right)+\beta E_{t} \frac{u_{c}\left(c_{t+1}, \xi_{t+1}\right)}{u_{c}\left(c_{t}, \xi_{t}\right)}\left(\pi_{t+1}-1\right) \pi_{t+1}
$$

Finally, the economy wide resource constraint sets output equal to the sum of consumption, government spending and the price adjustment costs so that :

$$
h_{t}=c_{t}+g_{t}+\frac{\theta}{2}\left(\pi_{t}-1\right)^{2}
$$


Our Ramsey planner seeks to maximize (2.1) subject to (2.6),(2.7) and (2.8). We attach a multiplier $\lambda_{s, t}$ to the budget constraint, $\lambda_{p, t}$ to the Phillips curve and $\lambda_{f, t}$ to the resource constraint. The Lagrangian for the planner's program is then given by:

$$
\begin{aligned}
& \mathcal{L}=E_{0} \sum_{t} \beta^{t}\left(u\left(c_{t}, \xi_{t}\right)+v\left(h_{t}\right)+\lambda_{f, t}\left(h_{t}-c_{t}-g_{t}-\frac{\theta}{2}\left(\pi_{t}-1\right)^{2}\right)\right. \\
& +\left(\lambda_{s, t-N}-\lambda_{s, t-N+1}\right) \frac{u_{c}\left(c_{t}, \xi_{t}\right)}{\prod_{t-N+1}^{t} \pi_{j}} b_{t-N}^{N}-\lambda_{s, t}\left(g_{t} u_{c}\left(c_{t}, \xi_{t}\right)-\left(w_{t} u_{c}\left(c_{t}, \xi_{t}\right) h_{t}+v_{h}\left(h_{t}\right) h_{t}\right)\right) \\
& \left.+\left(\lambda_{p, t-1}-\lambda_{p, t}\right) u_{c}\left(c_{t}, \xi_{t}\right) \pi_{t}\left(\pi_{t}-1\right)+\lambda_{p, t} \frac{\eta}{\theta} h_{t} u_{c}\left(c_{t}, \xi_{t}\right)\left(\frac{1+\eta}{\eta}-w_{t}\right)\right)
\end{aligned}
$$

for given $\lambda_{s,-N}, \ldots \lambda_{s,-1}$ and $\lambda_{p,-N}, \ldots \lambda_{p,-1}$. The first order conditions for this problem with respect to $c_{t}, b_{t}^{N}, h_{t}, w_{t}$ and $\pi_{t}$ are :

$$
\begin{aligned}
& u_{c}\left(c_{t}, \xi_{t}\right)-\lambda_{f, t}+\lambda_{s, t} u_{c c}\left(c_{t}, \xi_{t}\right)\left(w_{t} h_{t}-g_{t}\right)+\left(\lambda_{s, t-N}-\lambda_{s, t-N+1}\right) b_{t-N}^{N} \frac{u_{c c}\left(c_{t}, \xi_{t}\right)}{\prod_{t-N+1}^{t} \pi_{j}}= \\
& -\lambda_{p, t} \frac{\eta h_{t} u_{c c}\left(c_{t}, \xi_{t}\right)}{\theta}\left(\frac{1+\eta}{\eta}-w_{t}\right)+\left(\lambda_{p, t}-\lambda_{p, t-1}\right) u_{c c}\left(c_{t}, \xi_{t}\right) \pi_{t}\left(\pi_{t}-1\right) \\
& v_{h}\left(h_{t}\right)+\lambda_{f, t}+\lambda_{s, t}\left(w_{t} u_{c}\left(c_{t}, \xi_{t}\right)+v_{h h}\left(h_{t}\right) h_{t}+v_{h}\left(h_{t}\right)\right) \\
& +\lambda_{p, t} \frac{\eta}{\theta} u_{c}\left(c_{t}, \xi_{t}\right)\left(\frac{1+\eta}{\eta}-w_{t}\right)=0 \\
& \lambda_{s, t}-\frac{\eta}{\theta} \lambda_{p, t}=0 \\
& -\theta \lambda_{f, t}\left(\pi_{t}-1\right)-\sum_{k=1}^{N}\left(\lambda_{s, t-k}-\lambda_{s, t-k+1}\right) \beta^{N-k} E_{t} \frac{u_{c}\left(c_{t+N-k}, \xi_{t+N-k}\right) b_{t-k}^{N}}{\pi_{t} \Pi_{j=t-k+1}^{j=t+N-k} \pi_{j}} \\
& -\left(\lambda_{p, t}-\lambda_{p, t-1}\right) u_{c}\left(c_{t}, \xi_{t}\right)\left(2 \pi_{t}-1\right)=0 \\
& E_{t} \lambda_{s, t} \frac{u_{c}\left(c_{t+N}, \xi_{t+N}\right)}{\prod_{t+1}^{t+N} \pi_{j}}-E_{t} \lambda_{s, t+1} \frac{u_{c}\left(c_{t+N}, \xi_{t+N}\right)}{\prod_{t+1}^{t+N} \pi_{j}}=0
\end{aligned}
$$

Equations (2.10) and (2.11) are the planner's first order conditions for consumption and hours respectively whilst (2.13) determines the optimal inflation level. The first term in (2.13) captures the marginal impact of higher inflation on the resource costs associated with price changes. The second term measures the effect of higher inflation on the inherited liability of the government in period $t$ and the last term represents the intertemporal effects of a current change in inflation via the Phillips curve. In (2.12) the planner changes wages (marginal costs) so as to balance the benefits of higher wages in financing the deficit with the costs in terms of higher inflation in period $t$. Finally (2.14) is the Euler equation for the optimal choice of $b_{t}^{N}$. Following the argument in Aiyagari et al. (2002) the multiplier $\lambda_{s, t}$ behaves as a risk adjusted random walk. 


\subsection{Calibration}

Each period represents one calendar year with the discount factor $\beta$ set to 0.96 . We assume in period 0 the economy is in steady state with constant prices, consumption, government spending and hours and with the values for these variables such that they solve the system of first order conditions for the Ramsey policy problem. The steady state inflation rate is equal to zero, the level of government expenditure is set to $25 \%$ of value added, and the market value of debt equal to $60 \%$ of output. Since in the steady state the market value of debt is given by $\beta^{N} b^{N}$, as we vary the maturity $N$, we have to vary the quantity of bonds in the steady state to keep the market value constant. When we simulate the economy we choose initial conditions for $b_{t}^{N}, \lambda_{s, t}$ and $\lambda_{p, t}$ for $t=\{-N, \ldots,-1\}$ equal to the steady state values for these objects.

Household preferences are of the form $u\left(c_{t}, \xi_{t}\right)+v\left(h_{t}\right)=\xi_{t} \log \left(c_{t}\right)+\zeta \log \left(1-h_{t}\right)$. We choose $\zeta$ so that households spend $20 \%$ of their unitary time endowment working which gives $\zeta=3.0417$. $^{1}$

For price adjustment $\operatorname{costs} \theta$ we follow SGU (2004) and set $\theta=4.375$ which gives a linearized version of the Phillips curve consistent with the empirical estimates of Sbordone (2002). Taking log deviations of wages and inflation around the zero steady state inflation rate gives the Phillips curve:

$$
\hat{\pi}_{t}=\beta E_{t} \hat{\pi}_{t+1}-\frac{\bar{h}(1+\eta)}{\theta} \hat{w}_{t}
$$

where circumflexes denote log deviations from the steady state. To calibrate the elasticity $\eta$ we follow SGU (2004) and choose a value of -6 . Sbordone's empirical estimates imply a value of 17.5 for $\frac{\bar{h}(1+\eta)}{\theta}$ which with $\bar{h}=0.2$ implies a value for $\theta=17.5$. We divide by four to give an annual rate.

We assume the following stochastic processes for government spending and the preference shock :

$$
\begin{aligned}
& \ln g_{t}=\left(1-\rho_{g}\right) \ln \bar{g}+\rho_{g} \ln g_{t-1}+\varepsilon_{g, t}, \varepsilon_{g, t} \sim N\left(0, \sigma_{g}^{2}\right) \\
& \ln \xi_{t}=\left(1-\rho_{\xi}\right) \ln \bar{\xi}+\rho_{\xi} \ln \xi_{t-1}+\varepsilon_{\xi, t}, \varepsilon_{\xi, t} \sim N\left(0, \sigma_{\xi}^{2}\right)
\end{aligned}
$$

We calibrate $\rho_{i}$ and $\sigma_{i}$ for $i \in\{\xi, g\}$ so as to make the log-linearized version of our model consistent with estimates of the IS equation in Ireland (2004). ${ }^{2}$ In particular letting $i_{t}$ denote the short term interest rates the demand side equation in our model is given by:

$$
\beta\left(1+i_{t}\right) E_{t} \frac{c_{t}}{c_{t+1}} \frac{\xi_{t+1}}{\xi_{t}} \frac{1}{\pi_{t+1}}=1
$$

Log linearising this equation and imposing that in equilibrium $y_{t}=c_{t}+g_{t}+\frac{\theta}{2}\left(\pi_{t}-1\right)^{2}$ yields :

\footnotetext{
${ }^{1}$ Let $\bar{h}=0.2$ denote the steady state level of hours and $\bar{g}$ and $\bar{c}$ the analogous steady state values for government expenditure and consumption. The steady state market value of debt, $\beta^{N} \bar{b}$, is $60 \%$ of $\bar{h}$, which gives us $\bar{b}=\frac{6 \bar{h}}{\beta^{N}}$. The government budget constraint gives the appropriate value of $\zeta$ that is consistent with these targets since in the steady state it holds that: $\bar{b}\left(\beta^{N}-\beta^{N-1}\right)=\bar{g}-\frac{1+\eta}{\eta} \bar{h}\left(1-\frac{\zeta \bar{c}}{1-\bar{h}} \frac{\eta}{1+\eta}\right)$.

${ }^{2}$ Since he uses log consumption without government spending shocks the loading of the term $\left(\hat{\imath}_{t}-\right.$ $\left.E_{t} \hat{\pi}_{t+1}\right)$ is unity rather than $\frac{\bar{c}}{\bar{y}}$. Nevertheless his model seems to be the closest to ours in the empirical New Keynesian literature.
} 


$$
\widehat{y}_{t}=E_{t} \widehat{y}_{t+1}-\frac{\bar{c}}{\bar{y}}\left(\widehat{i}_{t}-E_{t} \widehat{\pi}_{t+1}\right)+\frac{\bar{g}}{\bar{y}} \widehat{g}_{t}+\frac{\bar{c}}{\bar{y}} \widehat{\xi}_{t}-E_{t} \frac{\bar{g}}{\bar{y}} \widehat{g}_{t+1}+\frac{\bar{c}}{\bar{y}} \widehat{\xi}_{t+1}
$$

where $\widehat{x}$ denotes the log deviation of variable $x$ from its steady state value.

Ireland (2004) estimates a version of this IS equation (along with a Phillips curve and an interest rate rule) using quarterly data for the US economy. In his analysis he leaves out government spending shocks and instead estimates the IS equation with only one disturbance. His estimates of the process for this unique shock map into our vector of disturbances with the linear combination $\frac{\bar{g}}{\bar{y}} \hat{g}_{t}+\frac{\bar{c}}{\bar{y}} \hat{\xi}_{t}$. In order to retrieve the implied process for $\xi_{t}$ we assume, following SGU (2004), that spending shocks have a standard deviation $\sigma_{g}=0.03$ in annual data and a first order autocorrelation $\rho_{g}=0.9$. Ireland (2004) on the other hand obtains a point estimate for the autocorrelation of $\frac{\bar{g}}{\bar{y}} \hat{g}_{t}+\frac{\bar{c}}{\bar{y}} \hat{\xi}_{t}$ equal to 0.947 . The value of 0.974 that would give us a yearly autocorrelation of 0.9 is within the range of his estimates. We therefore set $\rho_{g}=\rho_{\xi}=0.9$. Finally the standard deviation of the preference shock is obtained by mapping the yearly aggregated process into the quarterly estimates of Ireland (2004) giving a value of 0.0804 .

\section{Inflation, Debt Maturity and Debt Sustainability}

Our aim, in the context of a model with coordinated optimal monetary and fiscal policy, is to understand how the government uses inflation to achieve debt sustainability and how this changes as we vary the maturity structure of government debt. In this section, to help our focus on these issues, we consider a simplified version of our model in which there is only uncertainty in the first period. In other words, the economy is hit by an unanticipated shock to either government spending or preferences in period one and for all subsequent periods there is no uncertainty. We can solve this model exactly and use the first order condition to understand the properties of optimal inflation. We highlight two key channels through which inflation is used for fiscal purposes, a real liability effect and a channel that we refer to as an implicit profit tax.

The focus of this paper is inflation but we also briefly describe the behavior of tax rates and interest rates through which the government can achieve debt sustainability. As in Aiyagari et al (2002) the government in our model smooths the burden from distortionary taxation over time. As a result tax changes are peristent. As in Faraglia, Marcet and Scott (2012), the planner uses the tax schedule to alter consumption growth in order to influence interest rates and the debt financing costs. This additional channel is refered to as interest rate twisting.

\subsection{Expenditure Shocks}

We first consider the case of a shock to government expenditure. Under perfect foresight the government's intertemporal budget constraint is:

$$
-\sum_{t=1}^{\infty} \beta^{t-1}\left(g_{t} u_{c}\left(c_{t}, \bar{\xi}\right)-w_{t} u_{c}\left(c_{t}, \bar{\xi}\right) h_{t}-v_{h}\left(h_{t}\right) h_{t}\right)=\beta^{N-1} u_{c}\left(c_{N}, \bar{\xi}\right) \frac{b_{0}^{N} P_{0}}{P_{N}}
$$

In (3.1) we have replaced the product of inflation rates from period one to period $N$ with the ratio of initial and end prices. We also evaluate the budget constraint setting the preference shock to its steady state value, $\bar{\xi}$, so as to concentrate solely on the effects 
of changes in $g$. The government's intertemporal budget constraint equates the present discounted value of surpluses to the initial liability inherited by the government. After the unexpected shock, the government can either adjust tax revenue, or adjust the right hand side of (3.1) to ensure that it holds. Our focus here is on the properties of optimal inflation.

To determine the optimal path we assume the multipliers $\lambda_{s, t}$ and $\lambda_{p, t}$ have settled at their constant steady state values prior to the shock. From the martingale property of $\lambda_{s, t}$ we have $\lambda_{s, 0}=E_{0} \frac{u_{c}\left(c_{N}, \bar{\xi}\right) \lambda_{s, 1}}{P_{N}} / E_{0} \frac{u_{c}\left(c_{N}, \bar{\xi}\right)}{P_{N}}$ and from the first order condition with respect to wages $\lambda_{s, 0}=\lambda_{p, 0} \frac{\eta}{\theta}$. We assume the analogous values for the multipliers in periods $t=-N,-N+1,-1$ are equal to these period zero values. Since all uncertainty is removed after the shock $g_{1}$ from (2.14) it follows $\lambda_{s, t}=\lambda_{s, t+1} \forall t \geq 1$ and similarly from (2.12) $\lambda_{p, t}=\lambda_{p, t+1}$. As a result the first order condition for inflation is:

$$
\begin{aligned}
-\theta \lambda_{f, t}\left(\pi_{t}-1\right) & -\left(\lambda_{s, 0}-\lambda_{s, 1}\right) \beta^{N-t} \frac{u_{c}\left(c_{N}, \bar{\xi}\right) b_{0}^{N} P_{0}}{\pi_{t} P_{N}} \mathcal{I}(t \leq N) \\
& -\left(\lambda_{p, 1}-\lambda_{p, 0}\right) u_{c}\left(c_{t}, \bar{\xi}\right)\left(2 \pi_{t}-1\right) \mathcal{I}(t=1)=0
\end{aligned}
$$

where $\mathcal{I}(t=k)$ is an indicator function that takes the value one in period $k$ and zero otherwise.

This optimality condition is nonlinear and cannot be solved analytically but we can note some properties of the solution. First in (3.2) inflation responds to the $g$ shock for a maximum of $N$ periods. In period $t=N+1$ gross inflation satisfies $-\theta \lambda_{f, t}\left(\pi_{t}-1\right)=0$. In the case of sticky prices $\theta>0$ and $\lambda_{f, t} \neq 0$ so that inflation equals zero $\left(\pi_{t}=1\right)$. Therefore it is optimal for the planner to use inflation only for the duration of outstanding government debt.

From periods 1 to $N$ the term $\left(\lambda_{s, 1}-\lambda_{s, 0}\right) \beta^{N-t-1} \frac{u_{c}\left(c_{N}, \bar{\xi}\right) b_{0}^{N} P_{0}}{\pi_{t} P_{N}}$ determines optimal inflation as a function of the governments inherited liability and in particular the sign of the inflation response depends on whether governments are creditors or debtors. When $b_{0}^{N}>0$, the government wants to increase prices in response to a rise in $g_{1}$, so as to decrease the liability and absorb part of the shock. The converse holds if $b_{0}^{N}<0$. The higher is debt the higher is the level of optimal inflation. Therefore both the level and maturity of government debt matters when the government uses inflation through this real liability effect.

An additional influence on inflation operates through the term $\left(\lambda_{p, 1}-\lambda_{p, 0}\right) u_{c}\left(c_{1}, \bar{\xi}\right)\left(2 \pi_{1}-\right.$ 1 ) but only in period 1 . This term is related to the monopoly distortion in our model. When prices are sticky, increasing wages in high spending states serves to increase government revenue as labour income is taxed and reduces the monopoly distortion. The planner's incentive to do this only in the first period is driven by the motive to minimize inflation costs. Increases in wages beyond period 1 would contribute to government revenue. However, because of the expectation term in the Phillips curve they would result in an increase in inflation over several periods and so with additional costs which outweigh any fiscal gains.

We refer to this last effect as an implicit profit tax. To understand why note that, following SGU (2004), we have assumed the government is not able to tax firms' profits directly. If we do allow for a profit tax then this channel declines and in the limit disappears. To see this assume there a constant explicit profit tax rate $\tilde{\tau}$. In this case we can show 
the relevant first order condition on inflation is:

$$
\begin{gathered}
-\theta \lambda_{f, t}\left(\pi_{t}-1\right)-\left(\lambda_{s, 0}-\lambda_{s, 1}\right) \beta^{N-t} \frac{u_{c}\left(c_{N}, \bar{\xi}\right) b_{0}^{N} P_{0}}{\pi_{t} P_{N}} \mathcal{I}(t \leq N) \\
+\lambda_{s, t} \theta\left(\pi_{t}-1\right) u_{c}\left(c_{t}, \bar{\xi}\right) \tilde{\tau}-\left(\lambda_{s, 1}-\lambda_{s, 0}\right) u_{c}\left(c_{t}, \bar{\xi}\right)\left(2 \pi_{t}-1\right) \frac{\theta}{\eta}(1-\tilde{\tau}) \mathcal{I}(t=1)=0
\end{gathered}
$$

and the higher are corporate taxes the smaller this impact and in the limit, when $\tilde{\tau}=1$, the last term in (3.3) vanishes. ${ }^{3}$

These two forces - the real liability effect and an implicit profit tax - determine inflation dynamics and their impact depends on the sign of the shock $g_{1}$ as well as whether the government is a creditor or debtor and the maturity of debt. For example assume a positive innovation to government spending and $b_{0}^{N}>0$. In this case a rise in wages and inflation in period one helps the government reduce its debt and encourages labour supply. The two channels therefore work in the same direction in this case. However if $b_{0}^{N}<0$ the planner would like to reduce inflation to increase the value of savings but also increase wages and thus inflation to tax profits. Therefore when $b_{0}^{N}>0$ both forces serve to raise inflation but when $b_{0}^{N}<0$ the two forces push in different directions. If the government can issue longer term bonds, the trade-off between these two forces is less. Because the effective tax term applies only in period 1 if $N=1$ these two factors are in direct conflict. If $N>1$ then the government can commit to lower inflation between periods 2 and $N$ to meet both objectives.

To quantify these channels and to investigate how varying maturity works, in Figure 1 we show the optimal inflation path in our economy in response to a rise in spending (a one standard deviation shock) in the case of one period bonds (top left panel) and for a long bond where $N=10$ (top right panel). The initial shock is propagated through the first order autoregressive process so spending differs from $\bar{g}$ for several periods before it eventually converges back to its steady state value. The solid lines on both panels show the responses of inflation when the governments inherited liability is $60 \%$ of the steady state level of output, whereas the dashed lines represent an initial position of $-60 \%$ of output. ${ }^{4}$

[ Figure 1 About Here. ]

In line with our previous analysis, when $b_{0}^{N}>0$ (solid lines) the government commits to increase inflation for $N$ periods in response to the shock. In period one the response of prices is larger because the real liability effect and the profit tax effect point in the same direction. After period 1, in the case of the long bond, optimal inflation adjusts downwards, to reflect only the real liability effect.

When $b_{0}^{N}<0$ (dashed lines) prices increase with both maturities in period 1 due to the planners' incentive to tax profits. In our baseline calibration therefore the profit tax effect dominates the real liability effect in period 1 . Long bonds however permit the

\footnotetext{
${ }^{3}$ This equation generalizes to the case where $\tilde{\tau}=\tau_{t}$ that is when the government taxes profits at the same rate as labor income as in Lustig et al (2008).

${ }^{4}$ In (3.2) the optimal inflation path is influenced by the behavior of the multipliers which here evolve as pure random walks. This property is preserved independent of the first order autocorrelation coefficient of the process of government spending. As a result the optimal inflation path would be qualitatively very similar in the case of i.i.d innovations to $g_{1}$. We verified this numerically but for the sake of brevity do not report these results.
} 
government to commit to set gross inflation below unity for every subsequent period until period $N$ and so boost the value of assets. The price level increases by $0.045 \%$ after the shock in the short bond economy whereas in the long bond model it drops by $0.0521 \%$. In this case increasing maturity leads to lower inflation.

Notice that in either case the overall increase in prices, which is measured, in percentage points, is extremely modest. Prices increase by only 0.14 percentage points under $N=1$ and $b_{0}^{N}>0$ and whenever $N>1$ the planner would like to engineer an even smoother adjustment in inflation by spreading the burden across periods although increasing the maturity of debt does increase persistence. This result echoes the analysis of SGU (2004) who showed that when $N=1$ distortions from sticky prices dominate over tax smoothing concerns. Inflation in this case is not seen as an attractive mechanism with which to achieve fiscal sustainability.

\subsection{Preference Shocks}

We now consider the effects of an adverse shock to preferences, specifically a fall of $\xi_{t}$ relative to the steady state value $\bar{\xi}$. This shock will lower households appetite to consume leading to lower consumption and fewer hours worked. From the point of view of the government, a shock to preferences will lower tax revenue and will decrease the surplus of the government.

To illustrate the effects rewrite the government's intertemporal constraint as:

$$
-\sum_{t=1}^{\infty} \beta^{t-1}\left(\bar{g} u_{c}\left(c_{t}, \xi_{t}\right)-w_{t} u_{c}\left(c_{t}, \xi_{t}\right) h_{t}-v_{h}\left(h_{t}\right) h_{t}\right)=\beta^{N-1} u_{c}\left(c_{N}, \xi_{N}\right) b_{0}^{N} \frac{P_{0}}{P_{N}}
$$

Consider first the case $b_{0}^{N}>0$. A fall in $\xi_{1}$ relative to steady state means the LHS of (3.4) will decrease and as before movements in inflation and consumption can help the government smooth any required change in taxes. A negative innovation to $\xi_{1}$ will force the government to increase prices $P_{N}$ whereas if, in contrast, $b_{0}^{N}<0$ then the planner must adjust the liability by lowering prices. In both of these cases the government still has the incentive to vary the implicit profit tax through varying wages and inflation, and once more in the case where $b_{0}^{N}<0$ and the government issues short bonds the real liability effect and the implicit profit tax conflict contemporaneously.

We have so far shown that increasing maturity enables the government to make greater use of inflation, but in the case of preference shocks there is also a disadvantage to issuing longer bonds. Preference shocks impact asset prices and change the trade-off facing the government when it wishes to hedge against them using long maturities rather than short bonds. To illustrate this we rewrite the government's intertemporal budget constraint as:

$$
-\sum_{t=1}^{\infty} \beta^{t-1} \frac{u_{c}\left(c_{t}, \xi_{t}\right)}{u_{c}\left(c_{1}, \xi_{1}\right)}\left(g_{t}-w_{t} h_{t} \tau_{t}\right)=\beta^{N-1} \frac{u_{c}\left(c_{N}, \xi_{N}\right)}{u_{c}\left(c_{1}, \xi_{1}\right)} \frac{P_{0}}{P_{N}} b_{0}^{N}
$$

If $\xi_{1}<\xi_{N}$ the change in the marginal utility of consumption in periods 1 and $N$ may push the government's inherited liability in the opposite direction than the planner desires because of endogenous fluctuations in bond prices. When $b_{0}^{N}>0$ the planner would like to lower the value of debt. However if the shock is mean reverting, as we assumed, and relative movements in consumption are not large enough to compensate, then the ratio $\frac{u_{c}\left(c_{N}, \xi_{N}\right)}{u_{c}\left(c_{1}, \xi_{1}\right)}$ will rise and hence send the liability in the opposite direction. The longer is the 
maturity $N$, the more vulnerable the government is to this adverse effect. The only type of bond that is completely insulated from this effect is the one period bond, because its price is always equal to one independent of shocks. Whether shorter maturities help the government smooth the burden of taxation better than longer ones ultimately depends on how the importance of being able to use inflation more readily under long $N$ fares against the importance of these movements in the real returns.

In Figure 1 (bottom panels) we show the responses of inflation to the preference shock. The bottom left panel shows the optimal path in the short bond economy. Once again the solid line represents the path when the government has an initial position with positive debt and the dashed line shows an initial position with savings. The bottom right panel plots the analogous quantities in the short bond economy. Inflation follows a similar path as in the case of spending shocks although the magnitude of the adjustment of inflation is more than twice as large as under the fiscal shock. The reason for this is that preference shocks represent a much larger innovation to the governments budget all else equal, and therefore require a bigger adjustment in the policy tools that the planner has at their disposal.

\subsection{Response of the tax schedule}

In Figure 2 we plot the response of tax rates to both spending and preference shocks in our model. The left panels (top and bottom) correspond to the short maturity case and the right panels to the long bond economy. The top plots show how the tax schedule behaves after an unanticipated spending shock. The bottom plots show the analogous response to a preference shock. All figures correspond to the case of a positive initial liability $b_{0}^{N}>0$. Taxes increase after the shock and this increase persists even in the long run. Following Aiyagari et al (2002) this property reflects the random walk behavior of the multiplier $\lambda_{s, t}$, which in turn represents the excess burden of taxation. The government wants to smooth tax distortions by spreading the excess burden equally in expectation across periods. Both under preference and spending shocks there is a bigger rise in taxes in the initial period because taxes are influenced by the wage path as $\tau_{t}=1+\frac{v_{h}\left(h_{t}\right)}{u_{c}\left(c_{t} \xi_{t}\right) w_{t}}$. In the case of the preference shock the change in the value of $\xi_{t}$ also exerts an influence. The government postpones the rise in taxes so as to reduce the impact of the distortion on hours initially.

\section{[ Figure 2 About Here.]}

As explained in Faraglia Marcet and Scott (2012) in the long bond model there is an additional channel through which the government can achieve fiscal sustainability. The fall in the tax rate in period $N-1$ serves to increase consumption in that period and therefore lower the marginal utility $u_{c}\left(c_{N-1}, \xi_{N-1}\right)$. In effect the real value of the outstanding liability $\beta^{N} \frac{u_{c}\left(c_{N-1}, \xi_{N-1}\right)}{u_{c}\left(c_{1}, \xi_{1}\right)}$ drops and helps the government reduce the need to finance deficits through taxes. When debt is negative $b_{0}^{N}<0$, the planner pursues the opposite policy of increasing the tax rate. Following Faraglia Marcet and Scott (2012) we refer to this channel as interest rate twisting. 


\section{Stochastic Simulations}

Having outlined the key mechanisms at work in our model we now turn to full stochastic simulations to see how varying debt maturity influences the behaviour of inflation. We simulate the economy using random draws of government spending and preference shocks and study the cyclical behavior of optimal inflation, taxes and debt. As discussed in the previous section, these optimal paths will differ depending on the maturity structure and sign of government debt.

Our numerical approach to solve for the equilibrium is to approximate the conditional expectations in the first order conditions with polynomials of the appropriate state variables. In our application the state vector is a high dimensional object - it includes the value of government spending and the preference shock in period $t$, the history of debt obligations $b_{t-j}^{N}$, past values of the multipliers $\lambda_{s, t-j}$ and past values of gross inflation $\pi_{t-j}$ for $j=1, \ldots, N$. To give an idea of its size note that if the maturity of government bonds is 10 periods then the state space consists of 31 variables. Faraglia, Marcet and Scott (2012) show that in order to make the computation of models with large $N$ manageable one has to reduce the number of states in the approximating polynomials. Their approach is to partition the state space into variables that are of primary importance and variables of secondary importance. The latter are introduced in the approximating functions as successive linear combinations. The authors provide a procedure to test for the number of linear combinations that are necessary to get accurate approximations of the conditional expectation terms ${ }^{5}$.

The previous analysis suggested that the response of inflation to expenditure or preference shocks depends on the existing level of government debt. Therefore the range of positions that the government is allowed to take in the bond market will affect the cyclical properties of the variables of interest. To limit this range we assume that bond issuances are subject to ad hoc constraints of the form $\beta^{N} b_{t}^{N} \in\left\{\underline{M}_{N}, \bar{M}_{N}\right\}$. In the notation $\underline{M}_{N}$ is the lower value of the quantity of bonds that the government can issue in any given period and $\bar{M}_{N}$ is the corresponding upper bound. Because the government is assumed to buy back its debt each period, in the model $\underline{M}_{N}$ and $\bar{M}_{N}$ are bounds that correspond effectively to the overall liability of the government. Notice that since $\beta^{N}$ is the steady state market price of an $N$ period bond, these constraints are expressed in terms of the (steady state) market value of debt.

The results presented in this section derive from a model where $\frac{M_{N}}{\beta^{N}}=0$, meaning that the government can only borrow from the private sector. In Lustig et al. (2008) this constraint is imposed to ensure that the government cannot take extreme positions that would effectively complete the market as in Angeletos (2002). We also impose this constraint as we wish to focus on the case where the government has high debt but also in light of the findings of Faraglia et al. (2012) who show that allowing the government to go short or long in the case of only one asset leads to an equilibrium with a large accumulation of precautionary savings by the government.

\subsection{Simulation Results - Long Sample}

The model is run with one long sample of 100,000 observations. In Table 1 we show sample moments for four maturities - one, five, ten and twenty period bonds. All statistics are

\footnotetext{
${ }^{5}$ In the appendix we also address the accuracy of our numerical solution.
} 
calculated after dropping the first 5,000 observations so as to get rid of the influence of initial conditions.

The first two rows of Table 1 report the mean values of bonds and the market value of debt relative to the average value of output. Increasing debt maturity seems to have only a small impact on the market value of debt. As is expected, given our previous analysis, changing the maturity structure of debt changes the properties of the optimal inflation process. In row 4 we report the first order autocorrelation of inflation. As the maturity increases from one year to twenty years the correlation increases from 0.136 to 0.534 . The fact that inflation is positively autocorrelated even under one year maturity reflects the impact of the bounds on the government's optimal plan. ${ }^{6}$ We show in the appendix that near the no lending constraint the multiplier $\lambda_{s, t}$ ceases to behave as a risk adjusted random walk. In fact there is strong mean reversion in its response to shocks and evidently this adds to the persistence of the inflation process.

\section{[ Table 1 About Here.]}

In the third row of the table we report the standard deviation of inflation. This quantity increases with maturity from roughly $0.43 \%$ in the one year bond economy to $0.56 \%$ in the 20 year maturity model. However this is the unconditional standard deviation of inflation and so these differences reflect mainly differences in persistence. There is thus the following implication: that since the unconditional volatility effectively measures the overall price adjustment that the planner wants to engineer in response to shocks, lengthening the maturity even to twenty years does not translate into large price adjustments.

The last row of Table 1 shows the standard deviation of tax rates in the model. Longer maturities imply more volatile tax rates for two reasons. First, because tax rates are influenced by the behavior of wages as $\tau_{t}=1-\zeta \frac{1}{1-h_{t}} \frac{1}{u_{c}\left(c_{t}, \xi_{t}\right) w_{t}}$ and therefore more volatile inflation leads directly to more volatile taxes. The second reason is that in economies with long maturities the planner wants to use the tax schedule in order to control the marginal utility of consumption and so influence interest rates. According to Faraglia et al. (2012) this commitment to increase or lower taxes in a given period in the future adds to volatility.

\subsection{Does High Debt Encourage High Inflation?}

As discussed above the properties of inflation, taxes and the market value of debt are affected by the magnitude of government debt. In the stochastic model with one long sample the government on average issued little debt in terms of market value and as a consequence there was little difference between issuing short and long run debt. In this section we use short samples where we can condition on different levels of debt to better understand the impact on inflation. The results, summarized in Table 2 represent the moments from 1000 samples of 100 observations each run with different initial conditions uniformly distributed across the range $\left\{0, \frac{\bar{M}}{\beta^{N}}\right\}$. We report the properties of inflation when the initial condition is $0,30,60$ and 90 percent of average GDP. To conserve on space we only consider the case of 1 and 10 period bonds.

\footnotetext{
${ }^{6}$ In our simulations the lower bound is hit in roughly $4 \%$ of our sample. The upper bound is rarely hit (roughly .2\%) of all periods.
} 
[ Table 2 About Here.]

The top two rows of the table report the standard deviation and the first order autocorrelation of inflation in the case of debt with one year maturity. The bottom two report the analogous objects for maturity equal to ten years. As debt increases from $30 \%$ to $90 \%$ relative to GDP the volatility of inflation increases. The results from the short samples of this section give an indication of whether the optimal policy entails a large response of inflation to shocks when debt is high. The answer is "no". The sample volatility of inflation is $0.53 \%$ in the case of one year bonds and $0.60 \%$ with 10 year maturity in the case when initial debt is $90 \%$ relative to GDP. Price adjustments are therefore not large even in this case.

\section{Taylor Rule}

Our analysis so far has considered the case of a government implementing coordinated optimal monetary and fiscal policy under commitment. In the case where government issues $N$ period debt the key variables for policymakers are inflation rates from period $t$ to period $t+N-1$ and the marginal utilities of consumption in periods $u_{c}\left(c_{t}, \xi_{t}\right)$ and $u_{c}\left(c_{t+N-1}, \xi_{t+N-1}\right)$. Through these the planner can influence the price of an outstanding claim $\beta^{N-1} b_{t-1}^{N} \frac{u_{c}\left(c_{t+N-1}, \xi_{t+N-1}\right)}{u_{c}\left(c_{t}, \xi_{t}\right)} \frac{P_{t-1}}{P_{t+N-1}}$ and thereby the path of short and long term interest rates as well as inflation and hence the financing costs of debt. We have examined the behaviour of inflation under these conditions and found that there is a limited role for inflation, even with long maturity bonds.

However in practice governments face a variety of institutional constraints when setting their policies. One such constraint originates in the way monetary policy is conducted in many advanced economies whereby an (independent) central bank sets the target level of the nominal interest rate in response to changes in inflation or the difference of output from its potential. Second because the price of government debt is determined in asset markets, and possibly influenced by factors that are beyond the governments control, it is not obvious to what extend a commitment to a given policy for taxes and inflation can influence interest rates, as testified by the current Euro crisis. The lack of influence over bond prices is also institutionalised by the existence of separate debt management agencies who make decisions as to what maturity of debt to issue separately from decisions that are made regarding the size of the deficit. The type of bonds issued and their impact on bond prices is therefore considered separately in practice from fiscal decisions that set taxes and the deficit.

In this section we consider the behaviour of inflation and the role of debt maturity when we change some of the institutional assumptions behind our analysis. We assume the existence of an independent monetary authority that sets short term interest rates as a function of inflation and the output gap and we also assume the government cannot directly influence the price of nominal bonds or private sector expectations about the course of future inflation. The equilibrium of this model has a much smaller set of state variables characterizing government policy. Instead of having to keep track past and current values of the multipliers and bond quantities, only the inherited stock of debt from the last period $b_{t-1}^{N}$ and the shocks are in the state space. As we shall show this leads to a strong influence of the level of government debt on the path of inflation and taxes.

We formulate the government's problem as a Ramsey problem but in which the planner 
faces an additional constraint of the form:

$$
\left(\beta E_{t} \frac{u_{c}\left(c_{t+1}, \xi_{t+1}\right)}{u_{c}\left(c_{t}, \xi_{t}\right)} \frac{P_{t}}{P_{t+1}}\right)^{-1}=i_{t}=\frac{1}{\beta}\left(\frac{Y_{t}}{\bar{Y}}\right)^{\phi_{y}}\left(\pi_{t}\right)^{\phi_{\pi}}
$$

where $i_{t}$ denotes the gross nominal one period interest rate in the economy and $\phi_{y}$ and $\phi_{\pi}$ are coefficients that govern the response of interest rates to the output gap variable $\frac{Y_{t}}{Y}$ (expressed as deviation from its steady state level and which in our model is identical to $\frac{h_{t}}{\bar{h}}$ ) and inflation $\pi_{t}$ respectively. On the LHS of (5.1) we equate the nominal rate of interest to the inverse of the marginal rate of substitution of consumption between periods $t$ and $t+1$.

As the government is unable to control bond prices its budget constraint is:

$$
q_{t}^{N} b_{t}^{N}=q_{t}^{N-1} \frac{b_{t-1}^{N}}{\pi_{t}}+g_{t}-\left(1+\frac{v_{h}\left(h_{t}\right)}{u_{c}\left(c_{t}, \xi_{t}\right)}\right) w_{t} h_{t}
$$

and the Phillips curve is given by:

$$
\left.\pi_{t}\left(\pi_{t}-1\right)=\frac{\eta}{\theta} h_{t} u_{c}\left(c_{t}, \xi_{t}\right)\left(\frac{1+\eta}{\eta}-w_{t}\right)\right)+E_{t} \mathcal{F}
$$

where $\mathcal{F}=\beta \frac{u_{c}\left(c_{t+1}, \xi_{t+1}\right)}{u_{c}\left(c_{t}, \xi_{t}\right)} \pi_{t+1}\left(\pi_{t+1}-1\right)$ denotes inflation expectations for the next period. The planner will maximize households' utility subject to the resource constraint and (5.1), (5.2) and (5.3). We attach a multiplier $\lambda_{i, t}$ to the Taylor rule constraint and in an appendix derive the Lagrangian that describes the optimal allocation.

\section{Optimality Conditions.}

The first order conditions for the optimum are given by:

$$
\begin{aligned}
& u_{c}\left(c_{t}, \xi_{t}\right)-\lambda_{f, t}+\lambda_{s, t} u_{c c}\left(c_{t}, \xi_{t}\right)\left(\beta^{N} E_{t} \frac{u_{c}\left(c_{t+N}, \xi_{t+N}\right) P_{t}}{u_{c}\left(c_{t}, \xi_{t}\right) P_{t+N}} b_{t}^{N}-\beta^{N-1} E_{t} \frac{u_{c}\left(c_{t+N-1}, \xi_{t+N-1}\right) P_{t}}{u_{c}\left(c_{t}, \xi_{t}\right) P_{t+N-1}} b_{t-1}^{N}\right. \\
& -\lambda_{s, t} u_{c c}\left(c_{t}, \xi_{t}\right)\left(g_{t}-w_{t} h_{t}\right)-\lambda_{p, t} u_{c c}\left(c_{t}, \xi_{t}\right)\left(\pi_{t}\left(\pi_{t}-1\right)-\beta \frac{u_{c}\left(c_{t+1}, \xi_{t+1}\right)}{u_{c}\left(c_{t}, \xi_{t}\right)} \pi_{t+1}\left(\pi_{t+1}-1\right)\right)+ \\
& \left.+\lambda_{p, t} \frac{\eta}{\theta} h_{t} u_{c c}\left(c_{t}, \xi_{t}\right)\left(\frac{1+\eta}{\eta}-w_{t}\right)\right)=0 \\
& \left.v_{h}\left(h_{t}\right)+\lambda_{f, t}+\lambda_{s, t}\left(w_{t} u_{c}\left(c_{t} \xi_{t}\right)+v_{h}\left(h_{t}\right)+v_{h h}\left(h_{t}\right) h_{t}\right)+\lambda_{p, t} \frac{\eta}{\theta} u_{c}\left(c_{t}, \xi_{t}\right)\left(\frac{1+\eta}{\eta}-w_{t}\right)\right) \\
& +\lambda_{i, t} \frac{1}{\beta} \phi_{y} \frac{h_{t}^{\phi_{y}-1}}{\bar{h}^{\phi_{y}}} \pi_{t}^{\phi_{\pi}}=0 \\
& -\lambda_{f, t} \theta\left(\pi_{t}-1\right)+\lambda_{s, t} \beta^{N-1} E_{t} \frac{u_{c}\left(c_{t+N-1}, \xi_{t+N-1}\right) P_{t+1}}{P_{t+N}} \frac{b_{t-1}^{N}}{\pi_{t}^{2}}-\lambda_{p, t} u_{c}\left(c_{t}, \xi_{t}\right)\left(2 \pi_{t}-1\right) \\
& +\lambda_{i, t} \frac{1}{\beta} \phi_{\pi} \frac{h_{t}^{\phi_{y}}}{\bar{h}^{\phi_{y}}} \pi_{t}^{\phi_{\pi}-1}=0 \\
& \lambda_{s, t} E_{t} \frac{u_{c}\left(c_{t+N}, \xi_{t+N}\right)}{\pi_{t+1} \ldots \pi_{t+N}}=E_{t} \frac{\lambda_{s, t+1} u_{c}\left(c_{t+N}, \xi_{t+N}\right)}{\pi_{t+1} \ldots \pi_{t+N}}
\end{aligned}
$$


Equation (5.4) is the optimality condition for consumption, (5.5) for the choice of hours, (5.6) for inflation and (5.7) determines the choice of debt. ${ }^{7}$ Note that from (5.7) in an economy with only an initial shock (as in Section 3) $\lambda_{s, t}=\lambda_{s, t+1}$ holds whilst in general (5.7) suggests $\lambda_{s, t}$ follows a risk adjusted random walk so that tax distortions are persistent as they were under optimal policy in Section 2 . However, $\lambda_{s, t}$ exerts a different influence over the allocation in this case. Unlike in (3.2) it is the level and not the first difference of the multiplier which enters in (5.4) and (5.6). After a spending or preference shock it is the stock of debt in each period and not only the initial liability which influences the allocation, and changes in inflation continue even after period $t+N$. By assuming that the government cannot control bond prices and expectations of future inflation in this model, the planner does not internalise that higher inflation leads only to higher interest rates and so persists with inflation for longer than the case of optimal policy. Similarly with interest rates now set by the independent monetary authority the interest rate twisting of Faraglia, Marcet and Scott (2012) is no longer used to manipulate bond prices to minimise fluctuations in the excess burden of taxation. The kinks in the interest rate profile that arise from the government trying to alter the terms of its funding are overridden by the Taylor rule and the interest rate dynamics it provides. As well as overriding interest rate twisting, the Taylor rule also provides an additional objective to the planner - to smooth fluctuations in hours worked in response to shocks. To understand how this impacts on fiscal policy assume that the planner wishes to set $h_{t}=\bar{h}$ for each period after an adverse preference shock. Given the nature of this shock a fall in hours can be avoided by timing taxes appropriately. If $\xi_{t}$ falls the government would like to lower tax rates in every period where the influence of the shock is still present, and then increase them in the future in order to balance the budget. Ultimately whether the planner will sacrifice the goal to stabilize prices, now implicit in the Taylor rule, depends on the magnitude of the coefficients $\phi_{\pi}$ and $\phi_{y}$.

\subsection{Responses to Shocks}

To examine the model properties quantitatively we need to calibrate the coefficients $\phi_{\pi}$ and $\phi_{y}$ which we take from Rudebusch (2009) who estimates the following Taylor rule :

$$
\hat{\imath}_{t}=a_{0}+a_{1}\left(\hat{\pi}_{t}-\pi^{*}\right)+a_{2}\left(\hat{u}_{t}-\bar{u}^{*}\right)
$$

where $\hat{\imath}$ and $\hat{\pi}$ denote the nominal interest and inflation rate respectively; $\pi^{*}$ is the central banks inflation target and $\bar{u}^{*}$ is the natural rate of unemployment as defined by the Congressional Budget Office. According to Rudebusch (2009) a rise in the inflation rate by one percentage point leads to a rise in the interest rate by 1.3 percentage points and a rise in the unemployment rate by one percentage point reduces the interest rate by roughly $2 \%$.

In order to map (5.1) into (5.8) we take a first order Taylor expansion giving:

$$
\hat{\imath}_{t}=\gamma_{0}+\frac{\phi_{\pi}}{\beta}\left(\hat{\pi}_{t}-0\right)+\frac{\phi_{y}}{\beta \bar{h}}\left(h_{t}-\bar{h}\right)
$$

where the right hand side of (5.9) features hours not unemployment. To make the necessary transformation we assume aggregate hours are the product of a $60 \%$ employment

\footnotetext{
${ }^{7}$ The analogous first order condition for wages $w_{t}$ is unchanged relative to the model of section 2 and is therefore omitted for the sake of brevity.
} 
to population ratio multiplied by individual hours, which we normalize to a third of the unitary time endowment. Formally let $h_{t}=\left(1-U_{t}-L F_{t}\right) \frac{1}{3}$ where $L F_{t}$ denotes labor force participation and $U_{t}$ denotes the unemployment population ratio. To be consistent with an unemployment rate of $6.25 \%$ (average for the years 1994-2011 in the CPS) the mean level of $U_{t}$ is 0.04 . A first order approximation gives $h_{t}-\bar{h}=-\frac{1}{3}\left(U_{t}-\bar{U}\right)$ under the assumption that the labor force is constant over the business cycle ${ }^{8}$. Since $u_{t}=\frac{U_{t}}{L F_{t}}$ we get $\hat{u}_{t}-\bar{u}=\frac{1}{\overline{L F}}\left(U_{t}-\bar{U}_{t}\right)$. Making use of this derivation we get $\frac{\phi_{y}}{\beta \bar{h}} \frac{1}{3} \overline{L F}=2$ so that $\phi_{y}=1.8$. Finally since $\frac{\phi_{\pi}}{\beta}=1.3$ we obtain a value of the inflation coefficient equal to 1.248.

The top panels in Figure 3 plot the response of inflation to a positive innovation to government spending and the bottom panels plot the same for a negative innovation to the preference shock. The left panels corresponds to the short bond economy where we set $N=1$ and the right panels show the long bond model $(N=10)$. The solid lines in each figure are the actual responses in the Taylor rule model of this section. For the sake of comparison the responses under the optimal policy model are shown as dashed lines. As previously, after a spending or a preference shock, inflation increases but in contrast to the mechanisms identified in Section 2 the rise in inflation is now nearly permanent. As discussed the dynamics of government debt and the way the multiplier $\lambda_{s, t}$ enters the first order conditions in levels and not as a first difference are the key to understanding this sustained increase in inflation.

Our results also differ from previously in terms of how the response of inflation changes with the maturity of government debt. For example, when the spending shock hits and the government issues only short term debt inflation increases by roughly 0.2 percentage points initially and after 20 periods inflation is 0.23 percentage points above the steady state. In the $N=10$ economy these numbers are 0.1 and 0.118 respectively. In this case extending maturity leads to lower inflation. As a general rule the longer the maturity the smaller is the inflationary pressure to the economy. This difference can be traced to the behavior of the governments liability immediately after the shock. With $N=10$ a strong response of inflation in the first ten periods amounts to a huge adjustment of the inherited real stock of debt. But if $N=1$ then it is only the initial response of inflation that matters.

Figure 3 also shows considerable differences with the optimal commitment policy of Section 2. The impact of the preference shock on inflation is more than 6 times larger here. As discussed previously this is a consequence of the objective to smooth the effect of the shock on hours, measured by the coefficient $\phi_{y}$, and the definition of the output gap according to which the planner wishes to smooth deviations from the steady state level of hours $\bar{h}$. In the bottom panels of Figure 4 we show the response of the tax rate to the preference shock. The solid lines correspond to the model of this section. When the preference shock hits the economy, the tax rate must drop by nearly 15 percentage points regardless the maturity of the debt. Taxes rise above zero only after 20 periods when the influence of the shock nearly dies out. It is the drop of taxes that causes the government to run a deficit and not the response of hours, nearly constant after a fall of $\xi_{t}$.

Our calibration of the Taylor rule therefore suggests that in response to preference shocks the incentive to smooth hours dominates over price stability concerns. The rise of inflation is sizable precisely because price changes help to improve the governments fiscal position and therefore to hedge against the shock. However the results are sensitive to the

\footnotetext{
${ }^{8}$ Given that labor force participation does not have a strong cyclical component in the US this seems a reasonable assumption to make (see Veracierto (2008) and Shimer (2009)).
} 
specification of the Taylor rule. Suppose now we use a different output gap definition and we replace $\bar{h}$ with the complete market (efficient) output as the target for monetary policy. After the shock inflation increases to one percentage point if $N=1$ and roughly by 0.75 percentage points if $N=10$. The effect of the shock on inflation remains large at impact although it dies out more quickly. Regardless the structure of debt, the tax rate decreases on impact but the fall is shortlived. ${ }^{9}$

[ Figure 3 About Here.]

[ Figure 4 About Here.]

In the top panels of Figure 4 we show the time path of taxes after a spending shock. In this case the government wants to frontload tax distortions, since spending shocks lead to an initial slight increase in hours due to the familiar wealth effect.

\subsection{Stochastic Simulations}

In Table 3 we show key moments generated from a long sample of 100000 observations. The specification of the model is exactly that of Section 4 e.g. we impose a no lending constraint and an upper bound on debt of $100 \%$ of steady state GDP. The Table shows the model statistics under four different maturities; one, five, ten and twenty years.

\section{[ Table 3 About Here.]}

The top panel shows the case where the monetary authority sets the target for output equal to the steady state. As explained in the previous section, inflation volatility is considerably larger in this model. Moreover the standard deviation of inflation drops as we lengthen maturity. When $N=1$ the model produces a standard deviation of $19.95 \%$ but when $N=20$ this falls to $8.23 \%$. The persistence of inflation on the other hand shows little difference with maturity. In all cases we obtain a value of about 0.94 , substantially larger than the persistence implied by the optimal commitment policy of Section 4 .

In the bottom panel we show how the policy differs in the case where the Taylor rule sets the complete market output as the target. If markets are incomplete targeting the efficient outcome is not an easy task. Notice that as a result of the change in the target rule for the nominal interest rate the standard deviation of hours (output) increases considerably. The models generate a number for this quantity of around 0.025. In contrast when the output gap is given by $\frac{h_{t}}{\bar{h}}$ in the top panel, the standard deviation is tiny. Interestingly this gives rise to a discernible pattern of the volatility of tax rates by model specification and maturity. In the top panel of the table the volatility of tax rates is considerably higher and rises with maturity. In the bottom panel it drops with maturity. These results imply that the way the Taylor enters in the model is very important for the optimal allocation.

\footnotetext{
${ }^{9}$ We also experimented with a Taylor rule that sets $\phi_{\pi}=1.5$ and $\phi_{y}=0.5$. This specification yields a slightly greater incentive to stabilize prices. The rise in inflation to the preference shock is in the order of $1.6 \%$. Tax rates drop initially by roughly $8 \%$ and rise after 10 periods. We leave for future work the task of investigating how alternative specifications of the Taylor rule affect the results.
} 
To establish further that the monetary policy rule is an important constraint for the planner, we estimated the Taylor rule implied by the stochastic model of Section 4 . When maturity of debt is equal to one year the optimal commitment policy gave a value for $\phi_{y}=0.034$ and for $\phi_{\pi}=-1.04$. With $N=10$ we got $\phi_{y}=0.017$ and $\phi_{\pi}=-0.37$. Clearly the path of interest rates is quite different in the model of commitment with the empirically motivated Taylor rule placing a much greater concern towards output stability than in the unconstrained optimal policy problem where price stability is key.

\section{The Relative Importance of Inflation and Interest Rates}

In this section we examine the relative importance of inflation and interest rates in driving the behaviour of debt and assess how this varies as we change the maturity of government debt and the institutional environment. To answer this question we use the government budget constraint as in Hall and Sargent (2010) and decompose the change in the market value of debt following a shock to either spending or preferences into a component due to inflation and a component due to movements in interest rates.

The law of motion of the market value of debt is given by:

$$
\mathrm{MV}_{t}=\left(1-i_{t, N-1}(N-1)+i_{t-1, N} N-\hat{\pi}_{t}\right) \mathrm{MV}_{t-1}+g_{t}-w_{t} h_{t} \tau_{t}
$$

where $i_{t, j}$ is the maturity $j$ nominal interest rate $\left(\left(1+i_{t, j}\right)^{j}\right.$ is the inverse of the price of a bonf of maturity $j$ ). ${ }^{10} \hat{\pi}_{t}$ denotes net inflation in period $t$. In order to quantify the effect of interest rates and inflation we create two series. The first sets $\hat{\pi}_{t}$ equal to zero. The second sets $i_{t, N-1}$ and $i_{t-1, N}$ equal to their steady state values. Our accounting exercise is to look at percentage differences between these series and the market value of debt in (6.1).

Figure 5 shows the decomposition in the case of coordinated optimal monetary and fiscal policy. The top panels illustrate the dynamics of debt after the spending shock and the bottom panels after the preference shock. The left panels plot $N=1$ and the right ones $N=10$. The solid lines trace the effect of inflation as the percentage increase in the market value of debt that would have occurred had the inflation rate been held at its steady state value after the shock. The dashed lines represent the effects of interest rates.

Inflation has a small contribution towards sustainability of debt. Keeping inflation constant to zero with a short maturity and an increase in government spending, the market value of debt would be only 0.17 percentage points higher on impact and $0.35 \%$ after 15 periods. The results are similar when a long maturity is considered. In the case of

${ }^{10}$ To derive (6.1) we write the government budget constraint as follows:

$$
q_{t}^{N} b_{t}^{N}=q_{t-1}^{N} b_{t-1}^{N}+g_{t}-w_{t} h_{t} \tau_{t}=\frac{q_{t}^{N-1}}{q_{t-1}^{N}} q_{t-1}^{N} b_{t-1}^{N}+g_{t}-w_{t} h_{t} \tau_{t}
$$

Since $\mathrm{MV}_{t}=q_{t}^{N} b_{t}^{N}$ and $\frac{1}{q_{t}^{j}}=\left(1+i_{t, j}\right)^{j}$ we write $(6.2)$ as:

$$
\mathrm{MV}_{t}=\frac{\left(1+i_{t-1, N}\right)^{N}}{\left(1+i_{t, N-1}\right)^{N-1}} \frac{\mathrm{MV}_{t-1}}{\pi_{t}}+g_{t}-w_{t} h_{t} \tau_{t}
$$

Linearizing (6.3) we get (6.1) 
preference shocks we expect a greater contribution of inflation on the dynamics of debt because changes in prices are larger. However in the absence of inflation it takes 25 periods and a long maturity to have an effect of only two percentage points on debt. Therefore we can conclude that the contribution of price adjustments is modest.

Now we turn to the contribution of interest rates to debt dynamics. Interest rates, represented by the dashed lines in Figure 5, have a slightly larger effect than inflation. In the case of spending shocks keeping interest rates constant causes the market value of debt to increase by $0.3 \%$ if $N=1$ and by $0.6 \%$ points if $N=10$ (from 6.1 it takes one period for interest rates to have an effect if $N=1$ ). When we consider preference shocks the effect of interest rates is smaller. Although it persists to have a stronger influence in the dynamics of short term debt, the two margins (inflation and interest rates) bear an equal effect when long maturities are considered. Interest rates become a less effective policy tool when asset prices are influenced by a shock to $\xi_{t}$.

The level of initial debt does not affect the role of inflation on debt dynamics. Figure 6 shows the contribution of inflation and interest rates when the initial condition of debt is equal to $90 \%$ of GDP. Inflation continues to play a minor role when fiscal and monetary policies are coordinated.

[ Figure 5 About Here.]

[ Figure 6 About Here.]

The picture changes when we consider the case of uncoordinated fiscal and monetary policies (Figure 7). Removing the effect of inflation causes the market value of debt to increase more regardless the type of shock. In the case of spending shocks the government will have to increase short debt by $10 \%$ more and long debt by $5 \%$ after 25 periods. In the case of preference shocks constant inflation causes a more than doubling of debt over the same horizon. It is interesting to notice that interest rates have no contribution towards debt sustainability because they are no longer under the direct control of the government. All these results are reinforced when we consider a high initial conditions of debt (Figure 8).

The results presented in this section confirm the conclusions of the previous analysis: the institutional environment matters. When monetary and fiscal policy are coordinated the government has almost no incentive to use inflation as a debt stabilization instrument. However when the two policies are not coordinated inflation becomes a key instrument in driving debt dynamics.

[ Figure 7 About Here.]

[ Figure 8 About Here.] 


\section{Conclusions}

With currently high levels of government debt there is increasing interest and concern that governments may resort to inflation to achieve fiscal sustainability and that they are more likely to do so when they issue long maturity bonds. We consider the impact of the debt level and the debt maturity on inflation in a model of monopolistic competition and sticky prices building on the work of Schmitt-Grohe and Uribe (2004), Siu 2004) and Lustig, Sleet and Yeltekin (2008) and Faraglia Marcet and Scott (2012). We identify two key channels through which the government wants to use inflation for fiscal purposes, a real liability effect and an implicit profit tax. Using the computational method of Faraglia Marcet and Scott (2012) we are able to consider incomplete market models with debt of up to twenty years maturity. Our results suggest that when monetary and fiscal policies are jointly optimal in the sense that they are controlled by a single authority, debt and debt maturity have only a small impact on inflation. The optimal policy does not call for using inflation to reduce the deficit or lower the level of debt, but rather adjustments that follow shocks to the governments budget are accompagnied by persistent increases in tax rates. This result holds even for maturities as long as twenty years. If monetary and fiscal policies are uncoordinated, on the other hand, and the short term interest rate is set according to a Taylor rule our model assigns an important role to inflation. In response to shocks that lead to deficits the government wants to enginneer large and persistent increases in inflation. We show that the tax policy of the government is accomodative to the objective of output stability that is implicit in the Taylor rule. 


\section{Appendix}

\subsection{Numerical Procedures}

\section{One period uncertainty model.}

We briefly describe the numerical algorithm that we use to solve the one period uncertainty model of section 3. To simplify we assume that there is a shock to government spending (the algorithm to solve for preference shocks is identical). Our approach is to find a value for $\lambda_{s, 1}$ for every contingency $g_{1}$ and a value $\lambda_{s, 0}$ that satisfies the Euler equation (first order condition for bonds in period zero), such that after the shock the model economy converges to a long run steady state.

Step 1. Given initial conditions for $\lambda_{s, t}$ and $\lambda_{p, t}$ for $t=-N,-N+1, \ldots 0$, the initial value of the government real liability $b_{0}^{N}$, and a value of the spending process in period one $g_{1}$, we pick an initial value for $\lambda_{s, 1}$ and a simulation length $T$. We solve the system of optimality conditions to determine all of the endogenous variables from period 1 to period $T$. We assume that in period $T$ the economy converges to a new long run steady state. Notice that since the first order conditions involve both lags and expectations of endogenous variables, an inner loop is necessary to guarantee that the values of these variables converge.

Step 2. With the sequence of endogenous variables we construct the present value of the government's surplus in period one for each contingency $g_{1}$ as follows:

$$
\begin{gathered}
-\sum_{1}^{\infty} \beta^{T}\left(g_{t} u_{c}\left(c_{t}, \xi_{t}\right)-w_{t} u_{c}\left(c_{t}, \xi_{t}\right) h_{t}-v_{h}\left(h_{t}\right) h_{t}\right) \\
+\frac{\beta^{T+1}}{1-\beta}\left(g_{T} u_{c}\left(c_{T}, \xi_{T}\right)-w_{T} u_{c}\left(c_{T}, \xi_{T}\right) h_{T}-v_{h}\left(h_{T}\right) h_{T}\right)
\end{gathered}
$$

Convergence obtains when the surplus in 8.1 is close enough to the initial liability. Otherwise we need to update the value of $\lambda_{s, 1}$. We repeat steps 1 and 2 for every contingency $g_{1}$.

Step 3. We compute a new value for $\lambda_{s, 0}$. From the first order condition of $b_{0}^{N}$ the multiplier in period zero satisfies $\lambda_{s, 0}=E_{0} \frac{u_{c}\left(c_{N}, \xi_{N}\right) \lambda_{s, 1}}{\Pi_{1}^{N} \pi_{j}} / E_{0} \frac{u_{c}\left(c_{N}, \xi_{N}\right)}{\Pi_{1}^{N} \pi_{j}}$. To produce the figures in the main text we force the history of multipliers $\lambda_{s, t}$ and $\lambda_{p, t}$ for $t=\{-N, \ldots,-1\}$ to be equal to $\lambda_{s, 0}$ and $\lambda_{p, 0}$ respectively. We do this because we want to avoid having the endogenous variables in the model be affected by the initial conditions. ${ }^{11}$ With the new updated values of $\lambda_{s, 0}, \lambda_{p, 0}$ and $b_{0}^{N}$ we repeat steps 1 to 3 . The algorithm converges when successive updates of the date zero endogenous variables are not far apart.

\section{Stochastic Simulations Algorithm.}

We briefly describe the numerical procedure that we use to solve for the equilibrium in the model of section 4. Our algorithm is standard Parametrised Expectations algorithm as in Den Haan and Marcet (1990). Our approach is to approximate the condtional expectations in the first order conditions 2.14 to 2.13, the government budget constraint and the Phillips curve with polynomials of the states. For example we approximate the

\footnotetext{
${ }^{11}$ Otherwise the system of first order condions in the one period uncertainty model would include the terms $\lambda_{s,-1}-\lambda_{s, 0}$ and $\lambda_{p,-1}-\lambda_{p, 0}$.
} 
terms $E_{t} \frac{u_{c}\left(c_{t+k}, \xi_{t+k}\right)}{\Pi_{1}^{k} \pi_{t+j}}$ for $k=1, \ldots N$, with a functional form $\Phi\left(X_{t}, \delta^{k}\right)$ where $X_{t}$ denotes the state vector in period $t$, and $\delta^{k}$ is the vector of coefficients attached to these polynomials.

The algorithm proceeds as follows: First we pick an order of the polynomial and initial values for the coefficients $\delta_{0}^{k}$. We use these objects to solve the system of first order conditions of the Ramsey problem. We store the simulated series for consumption, bonds, inflation and the multipliers. With the simulated paths we create the integrands in the conditional expectation terms (for example the term $\frac{u_{c}\left(c_{t+k}, \xi_{t+k}\right)}{\Pi_{1}^{k} \pi_{t+j}}$ ). To update the coefficients in $\delta^{k}$ we regress these expressions on the state variables in $X_{t}$. This gives us a new set of coefficients $\delta_{1}^{k}$. We iterate on this procedure until we obtain convergence in the coefficients.

We mentioned in the main text that ours is a large scale application with many of state variables. To give an idea of the size of $X_{t}$ note that if $N=10$ there are 31 state variables in the model. To reduce the number of state variables used in the approximating functions we apply the methodology of Faraglia Marcet and Scott (2012). The formal description of the algorithm and an application to an economy with real debt is contained in that paper.

Finally when we introduce bounds in the stochastic simulations we treat them as follows: The condition $\beta^{N} b_{t}^{N} \in\{\underline{M}, \bar{M}\}$ implies that the Euler equation of government debt will not be satisfied with equality when the constraint binds. To see this consider the planners problem outlined in section 2 but add to it two constraints of the form $v_{1, t}\left(b_{t}^{N}-\frac{\bar{M}_{N}}{\beta^{N}}\right)$ and $v_{2, t}\left(\frac{M_{N}}{\beta^{N}}-b_{t}^{N}\right) . v_{1, t}$ and $v_{2, t}$ are the corresponding multipliers of the debt and upper and lower bound constraints. The first order condition for $b_{t}^{N}$ is given by:

$$
\beta^{N}\left(E_{t} \lambda_{s, t} \frac{u_{c}\left(c_{t+N}, \xi_{t+N}\right)}{\prod_{t+1}^{t+N} \pi_{j}}-E_{t} \lambda_{s, t+1} \frac{u_{c}\left(c_{t+N}, \xi_{t+N}\right)}{\prod_{t+1}^{t+N} \pi_{j}}\right)+v_{1, t}-v_{2, t}=0
$$

which clearly shows how hitting the bounds invalidates the risk adjusted random walk property of the multiplier $\lambda_{s, t}$. In fact as we explained in the text, in our simulations we found that near these bounds, the multiplier $\lambda_{s, t}$ displays strong mean reverting behavior. In order to deal with the bounds our approach is to replace $b_{t}^{N}=\frac{\bar{M}_{N}}{\beta^{N}}$ or $b_{t}^{N}=\frac{M_{N}}{\beta^{N}}$ when the bound is hit (clearly both bounds cannot be hit simultaneously) and use the remaining first order conditions along with the Phillips curve, the budget constraint and the resource constraint to determine the endogenous variables.

\subsection{Accuracy of the solutions}

In order to access the accuracy of our solution of our optimal model we perform two tests: we evaluate the Euler Equation Errors (Judd (1998)) generated by our model and we perform an informal Den Haan and Marcet test (1994).

Here we present results for the optimal model solved with Parameterised Expectations in Section 4. First we calculate the Euler Equation Errors. Given our approximated policy function, $\phi\left(s_{t}\right)$, where $s_{t}$ is the vector of state variables, we simulate the model for $N=5,10$ and 20 for $T=200000$ and we evaluate the Euler Equation Errors in $\hat{T}=1000$ points equally spaced in the sample. For every $\hat{t}$ we recalculate the conditional expectations 
using $\phi\left(s_{t}\right)$ :

$$
\begin{aligned}
R_{1} & =\frac{E_{\hat{t}}\left(\lambda_{s, \hat{t}+1} \frac{u_{c}\left(c_{\hat{t}+N}, \xi_{\hat{t}+N}\right)}{\Pi_{j=\hat{t}+1}^{t+N} \pi_{j}}\right)}{E_{\hat{t}}\left(\frac{u_{c}\left(c_{\hat{t}+N}, \xi_{\hat{t}+N}\right)}{\Pi_{j=\hat{t}+1}^{t+N} \pi_{j}}\right)} \\
R_{2} & =E_{\hat{t}}\left(\frac{u_{c}\left(c_{\hat{t}+N}, \xi_{\hat{t}+N}\right)}{\prod_{j=\hat{t}+1}^{\hat{t}+N} \pi_{j}}\right) \\
R_{3} & =E_{\hat{t}}\left(\frac{u_{c}\left(c_{\hat{t}+N-1}, \xi_{\hat{t}+N-1}\right)}{\prod_{j=\hat{t}+1}^{\hat{t}+N-1} \pi_{j}}\right) \\
R_{4}= & E_{\hat{t}}\left(u_{c}\left(c_{\hat{t}+N}, \xi_{\hat{t}+N}\right)\left(\pi_{\hat{t}+1}-1\right) \pi_{\hat{t}+1}\right) .
\end{aligned}
$$

drawing 50000 realizations of the shocks for every $j=\hat{t}+1, . ., \hat{t}+N$, using $\phi\left(s_{t+j}\right)$ to pin down the allocation in every period and performing a Montecarlo integration. Given the new expectations we recalculate the implied solution for period $\hat{t}$ and evaluate the percentage difference between the allocation given by the approximated policy rule $\phi\left(s_{t}\right)$ and the one implied by $R_{1}, R_{2}, R_{3}$ and $R_{4}$. The results are reported in Tables 4 to 6 . Table 4 reports the average of the Euler Equation Errors $\left(E E E_{\hat{t}}=\left|\frac{\omega_{i, \hat{t}}-\omega_{i, \hat{t}}^{\text {impl }}}{\omega_{i, \hat{t}}}\right|\right)$ implied by the three Euler equations of the model in terms of the multiplier of the government budget constraint, $\omega_{1}=\lambda_{s}$, and the gross nominal interest rates for maturity $N$ and $N-1$, $\omega_{2}=i^{N}$ and $\omega_{3}=i^{N-1}$. The results show that the errors are low and the approximations are accurate. Moreover in all the models roughly $50 \%$ of the errors have a positive sign highlighting that the errors are equally distributed around the average. We have also checked that more than $90 \%$ of the times the errors are below one percent and no bigger than $2 \%$. To further evaluate the accuracy of the solution we report the average and the standard deviation of some key variables generated by our approximation and the ones implied by $R_{1}, R_{2}, R_{3}$ and $R_{4}$. Tables 5 and 6 report the results. The averages are close to each other as well as the standard deviations. This evidence confirms that our approximation is accurate.

\section{[ Tables 4, 5 and 6 About Here ]}

To further reinforce this result we check the accuracy of our method by performing some simple, informal tests based on the insights of Den Haan and Marcet (1994). We run $N N=10000$ simulations of $T=3500$ periods, of which we discard the first 500 before reporting the statistics using our approximation. We calculate:

$$
\begin{gathered}
\varepsilon_{t}^{1}=\lambda_{s, t} \frac{u_{c}\left(c_{t+N}, \xi_{t+N}\right)}{\prod_{j=t+1}^{t+N} \pi_{j}}-\lambda_{s, t+1} \frac{u_{c}\left(c_{t+N}, \xi_{t+N}\right)}{\prod_{j=t+1}^{t+N} \pi_{j}} \\
\varepsilon_{t}^{2}=p_{t}^{N}-\frac{u_{c}\left(c_{t+N}, \xi_{t+N}\right)}{\prod_{j=t+1}^{t+N} \pi_{j}} \\
\varepsilon_{t}^{3}=p_{t}^{N-1}-\frac{u_{c}\left(c_{t+N-1}, \xi_{t+N-1}\right)}{\prod_{j=t+1}^{t+N-1} \pi_{j}} .
\end{gathered}
$$


If the solution is accurate, then these errors should be small relative to the long run average of the multiplier and the the bond prices respectively. Table 7 reports these ratios and all the results indicate a good accuracy.

\section{[Table 7 About Here ]}

\subsection{Ramsey Problem for the Model of section 5}

In this section we briefly describe how we set up the planners program in the model of section 5. As we explained in the text the government cannot control bond prices and expectations of future inflation and faces the additional constraint of the monetary policy rule. We attach a multiplier $\lambda_{i, t}$ to that constraint.

The budget set of the government is off the following form:

$$
q_{t}^{N} b_{t}^{N}=q_{t}^{N-1} \frac{b_{t-1}^{N}}{\pi_{t}}+g_{t}-\left(1+\frac{v_{h}\left(h_{t}\right)}{u_{c}\left(c_{t}, \xi_{t}\right)}\right) w_{t} h_{t}
$$

and further on the Phillips curve is given by:

$$
\left.\pi_{t}\left(\pi_{t}-1\right)=\frac{\eta}{\theta} h_{t} u_{c}\left(c_{t}, \xi_{t}\right)\left(\frac{1+\eta}{\eta}-w_{t}\right)\right)+E_{t} \mathcal{F}
$$

where $\mathcal{F}=\beta \frac{u_{c}\left(c_{t+1}, \xi_{t+1}\right)}{u_{c}\left(c_{t}, \xi_{t}\right)} \pi_{t+1}\left(\pi_{t+1}-1\right)$, is the inflation expectation for the next period. We multiply both 8.3 and 8.4 by the marginal utility of consumption $u_{c}\left(c_{t}, \xi_{t}\right)$. The Lagrangian can be written as:

$$
\begin{aligned}
\mathcal{L}=E_{0} \sum_{t} \beta^{t}\left(u\left(c_{t}, \xi_{t}\right)+v\left(h_{t}\right)\right. & +\lambda_{f, t}\left(h_{t}-c_{t}-g_{t}-\frac{\theta}{2}\left(\pi_{t}-1\right)^{2}\right) \\
+\lambda_{s, t} u_{c}\left(c_{t}, \xi_{t}\right)\left(b_{t}^{N} q_{t}^{N}-b_{t-1} \frac{q_{t}^{N-1}}{\pi_{t}}\right) & -\lambda_{s, t}\left(g_{t} u_{c}\left(c_{t}, \xi_{t}\right)-\left(w_{t} u_{c}\left(c_{t}, \xi_{t}\right) h_{t}+v_{h}\left(h_{t}\right) h_{t}\right)\right) \\
-\lambda_{p, t}\left(u_{c}\left(c_{t}, \xi_{t}\right)\left(\pi_{t}\left(\pi_{t}-1\right)-\mathcal{F}\right)\right. & \left.+\lambda_{p, t} \frac{\eta}{\theta} h_{t} u_{c}\left(c_{t}, \xi_{t}\right)\left(\frac{1+\eta}{\eta}-w_{t}\right)\right) \\
& +\lambda_{i, t}\left(\frac{1}{\beta}\left(\frac{h_{t}}{\bar{h}}\right) \pi_{t}^{\phi_{y}}-i_{t}\right)
\end{aligned}
$$

It is straightforward to show that taking the first order conditions from 8.5 and substituting out prices leads to equations 5.4 to 5.7 in the main text. The planners program is easy to extend in order to incorporate debt limits as we described above. 
Aiyagari, R., Marcet, A., Sargent, T.J. and Seppala, J. (2002) "Optimal Taxation without State-Contingent Debt" Journal of Political Economy, 110, 1220-1254

Aizenman. J. and Marion. N (2009) "Using Inflation to Erode the US Public Debt" NBER Working Paper No 15562

Angeletos, G-M (2002) "Fiscal Policy with Non-Contingent Debt and Optimal Maturity Structure", Quarterly Journal of Economics, 27, 1105-1131

Barro, R.J. (1979) "On the Determination of the Public Debt", Journal of Political Economy, 87, 940-71.

Buera F. and J.P. Nicolini (2004) "Optimal Maturity of Government Debt with Incomplete Markets", Journal of Monetary Economics, 51, 531-554

Den Haan, W. and Marcet, A. (1990) "Solving the Stochastic Growth Model by Parameterizing Expectations" Journal of Business and Economic Statistics, 8, 31-34.

Den Haan, W. J and Marcet, A., (1994). "Accuracy in Simulations," Review of Economic Studies, Wiley Blackwell, vol. 61(1), 3-17.

Faraglia, E., Marcet, A. and Scott. A (2008) "Fiscal Insurance and Debt Management in OECD Economics "Economic Journal, 118 (525), 363-386.

Faraglia, E., Marcet, A. and Scott. A (2012) "Debt Management and Optimal Fiscal Policy with Long Bonds", BIS Papers no.65, "Threat of Fiscal Dominance?", May 2012

Giannitsarou. C. and Scott. A (2007) "Inflation Implications of Rising Government Debt" , NBER Working Paper No. 12654.

Hall. G. J. and Sargent. T (2010) "Interest Rate Risk and Other Determinants of Post-WWII U.S. Government Debt/GDP Dynamics", NBER Working Paper No. 15702

Judd, K. (1998) "Numerical Methods in Economics", MIT Press Books, The MIT Press, edition 1, volume 1, number 0262100711.

Ireland, P (2004) "Technology Shocks in the New Keynesian Model ", Review of Economics and Statistics 86, (4), 923-936

Lucas, R.E. and Stokey, N.L. (1983) "Optimal Fiscal and Monetary Policy in an Economy without Capital", Journal of Monetary Economics, 12, 55-93.

Lustig. H., Christopher Sleet. C., and Yeltekin. S (2008) 'Fiscal Hedging with Nominal Assets', Journal of Monetary Economics 55, (4), 710-727

Reinhart, C and Rogoff, K. (2011) "This Time Is Different: Eight Centuries of Financial Folly" Princeton University Press, Princeton, NJ 
Rudebusch, G. (2009) "The Fed's Monetary Policy Response to the Current Crisis", FRBSF Economic Letter, 2009-17

Sbordone, A. M., (2002) "Prices and Unit Labor Costs a New Test of Price Stickiness", Journal of Monetary Economics, 49, 265-292

Schmitt-Grohe. S. and Uribe. M (2004) "Optimal Fiscal and Monetary Policy Under Sticky Prices", Journal of Economic Theory, 114 198-230

Shimer, R. (2009) "Convergence in Macroeconomics: The Labor Wedge " American Economic Journal: Macroeconomics, 1(1), 280-297

Siu. H (2004) "Optimal Fiscal and Monetary Policy with Sticky Prices" Journal of Monetary Economics, 51, 575-607

Veracierto, M. (2008) "On the Cyclical Behavior of Employment, Unemployment and Labor Force Participation "Journal of Monetary Economics, Vol 55, 1143-1157 

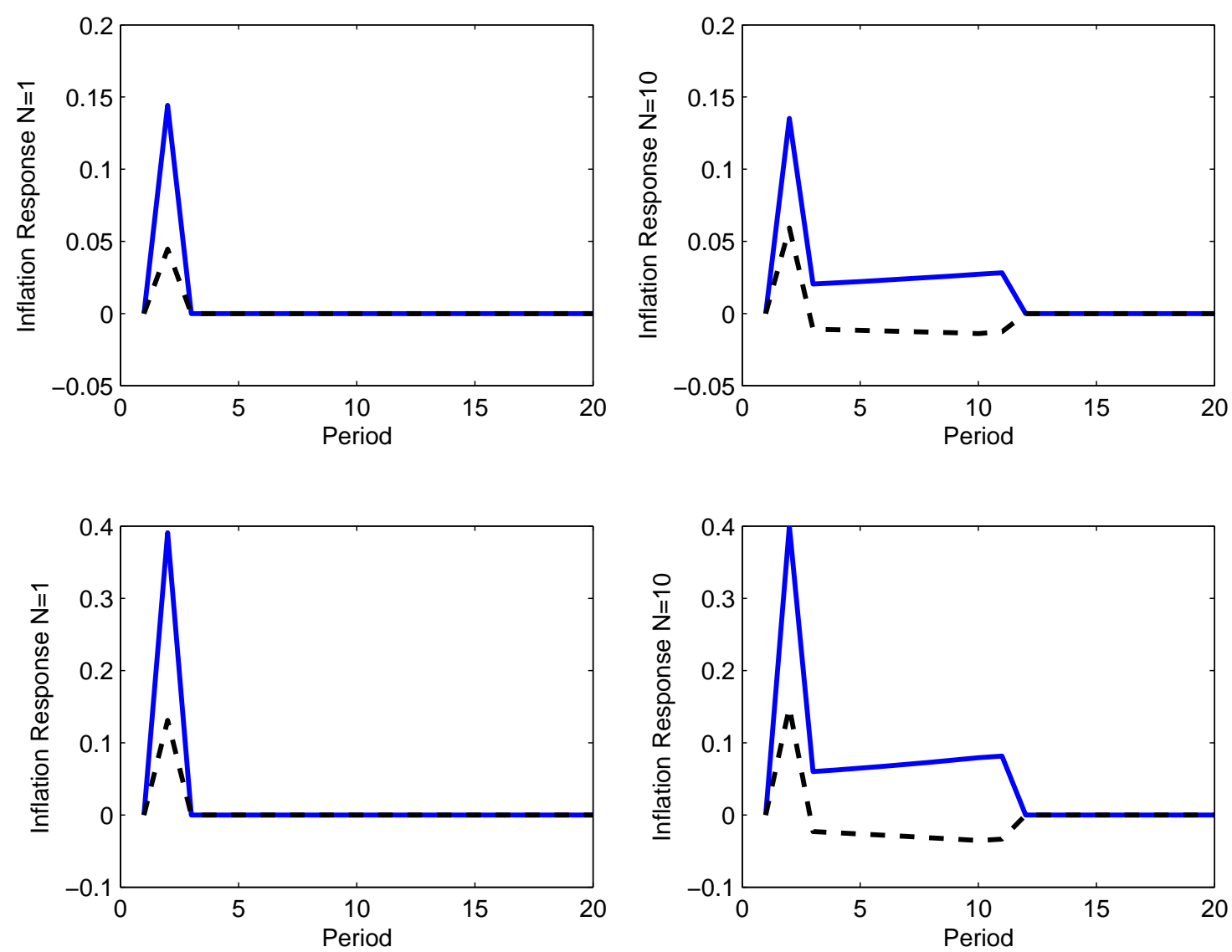

The left panels show the optimal inflation path for the short bond economy $(N=10)$. The solid lines represent the inflation path when the governments inherited liability $b_{0}^{N}$ is $60 \%$ of the steady state GDP in market value. The dashed lines show the analogous path starting from initial position of - $60 \%$ of GDP. The right panels show the responses for the long maturity ( $N=10$ ). Top plots correspond to the spending shock. Bottom plots show the responses for the preference shock.

Figure 1: Reponses of inflation to spending and preference shocks 

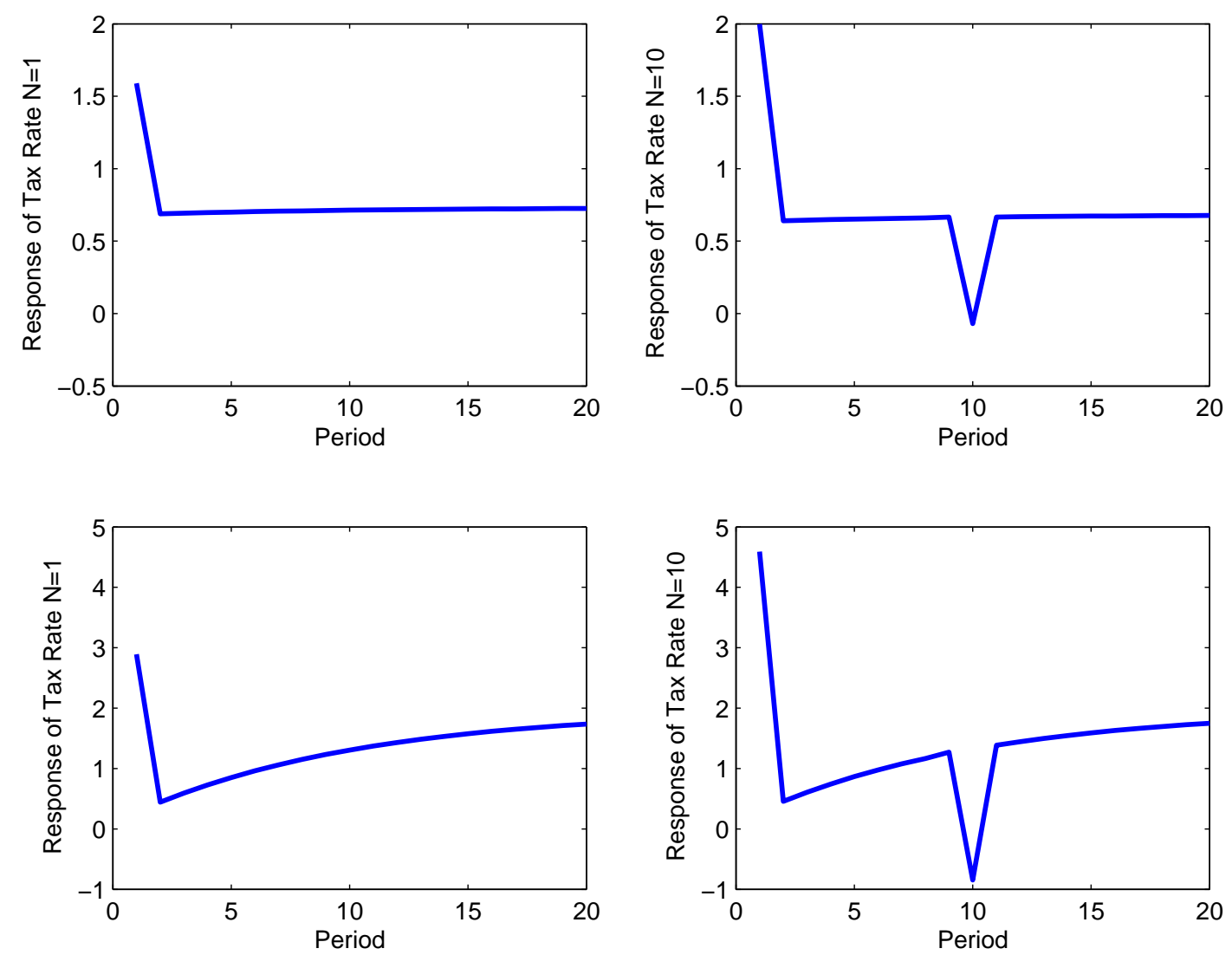

The right panel shows the optimal tax schedule for the long bond economy ( $N=10$ ). The left panels represent the short bond model. The top two plots correpond to the spending shock. The bottom to the preference shock.

Figure 2: Reponses of tax rates to spending and preference shocks 

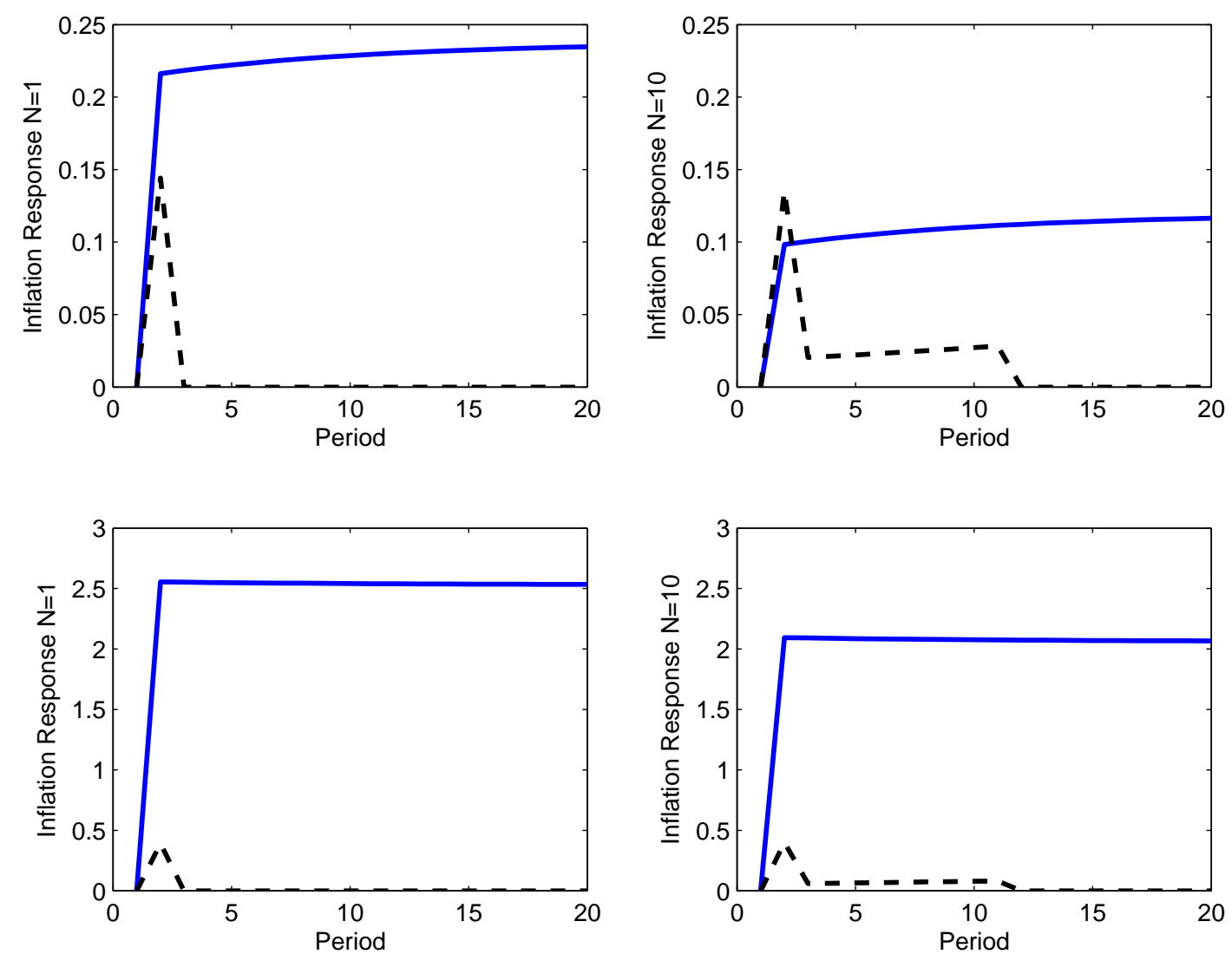

The right panels (top and bottom) show the case of the one period bond economy. The left ones show the case of $N=10$. The solid lines represent the inflation response under the Taylor rule economy. The dashed lines plot the analogous response under the optimal policy for the sake of comparison. The figures are generated assuming an initial level of the governments inherited liability equal to $b_{0}^{N}$ is $60 \%$ of the steady state GDP in market value. Top panels show responses to spending shocks. Bottom panels show responses to preference shock.

Figure 3: Reponses of inflation to spending and preference shocks 

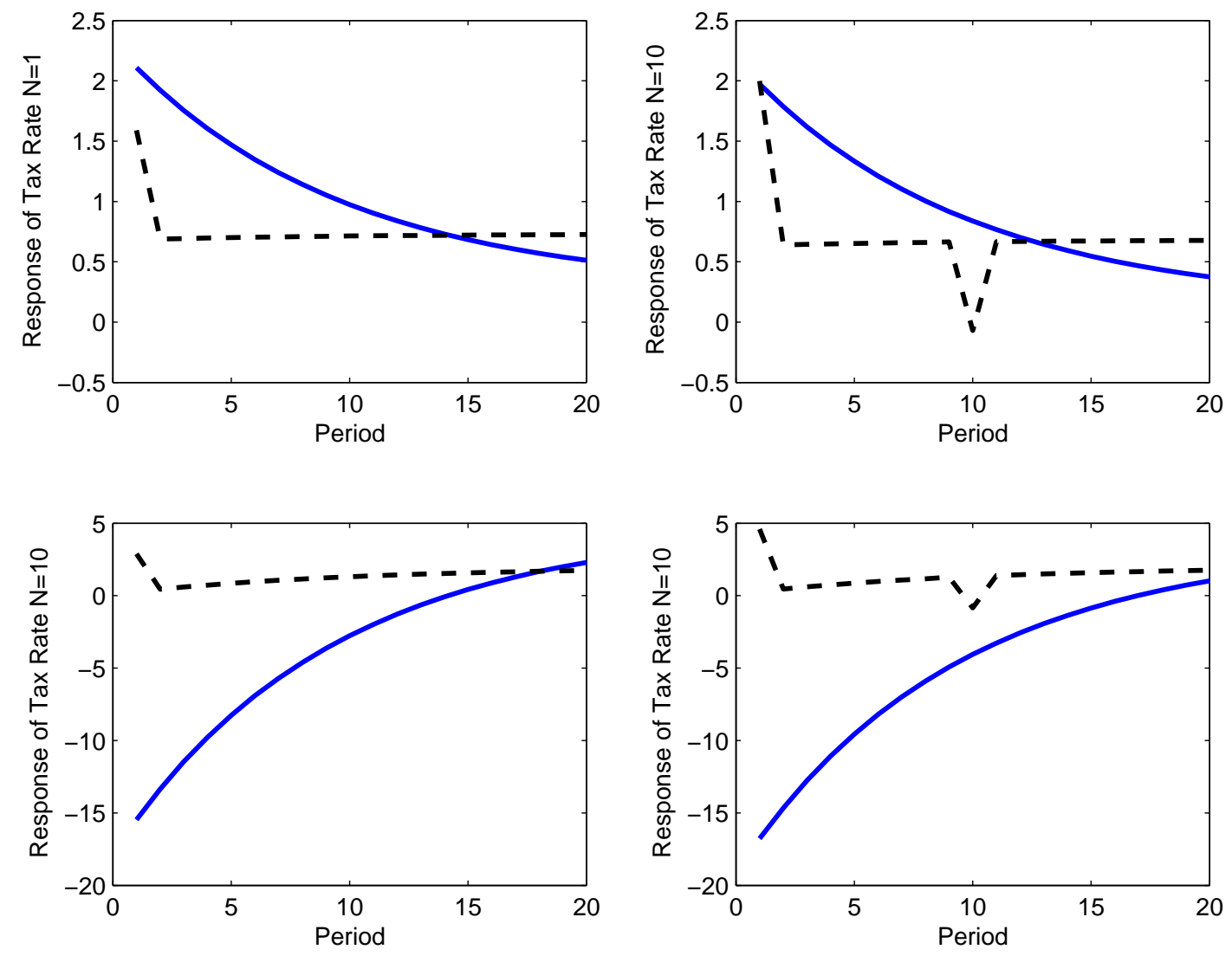

The left panels show the case of the one period bond economy. The right panels show the case of $N=10$. The solid lines represent the inflation response under the ucoordinate monetary and fiscal policy model. The dashed line (right axis) plots the analogous response under the optimal coordinated policy. The top plots show the response of the tax schedule to the spending shock. The bottom plots are the analogous responses to the preference shock. The figures are generated assuming an initial level of the governments inherited liability equal to $b_{0}^{N}$ is $60 \%$ of the steady state GDP in market value.

Figure 4: Reponses of tax rates to spending and preference shocks 

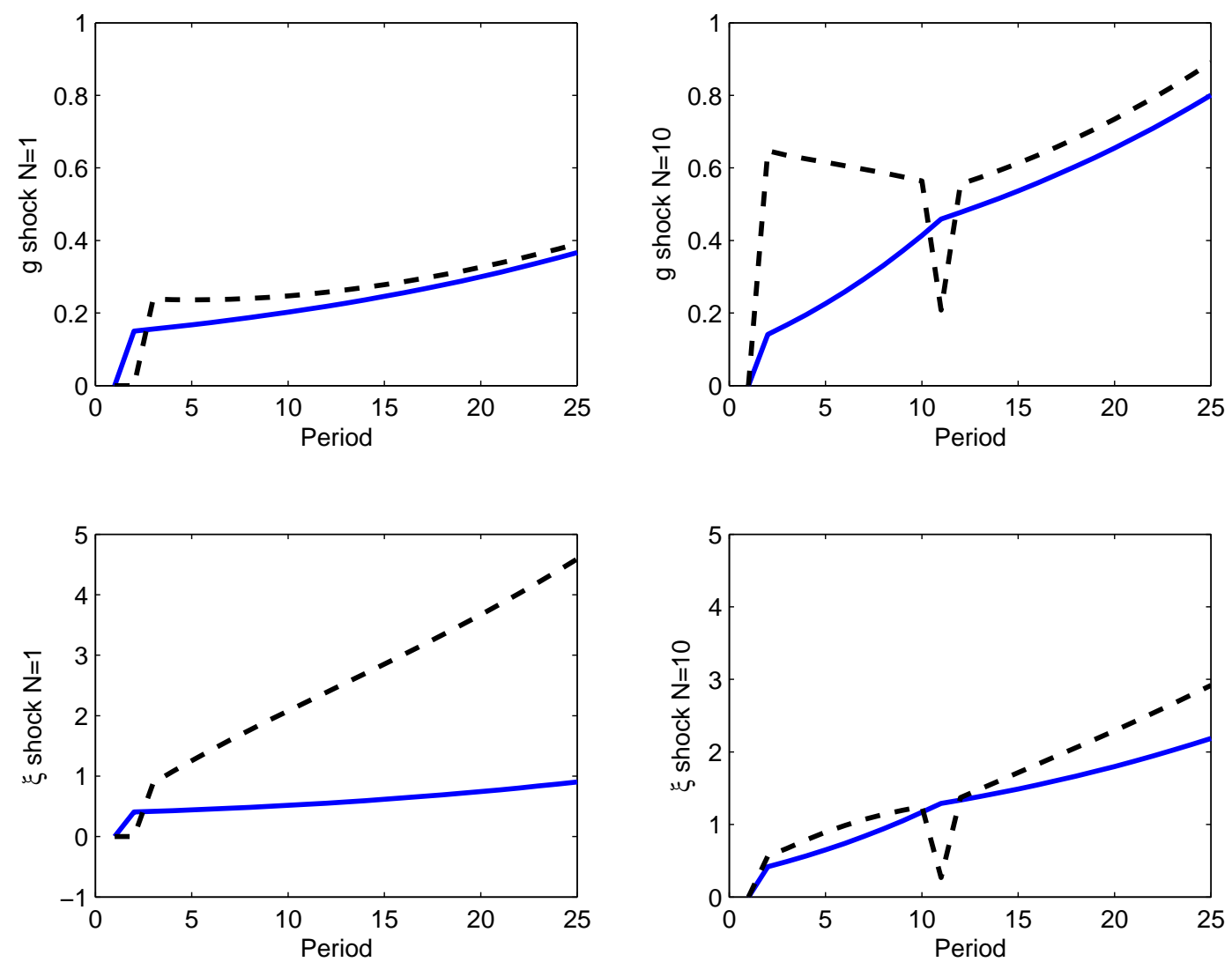

The top panels plot the decomposition after a spending shock for $N=1$ (left) and $N=10$ (right). The bottom panel shows the decomposition after the preference shock. The solid line illustrates the dynamics of the market value (in percentage changes relative to the actual market value) when we remove the influence of inflation. The dashed line illustrates the behavior of debt if inflation is the only variable that contributes to debt dynamics.

Figure 5: Debt Decomposition: Responses of the Market Value of Debt 

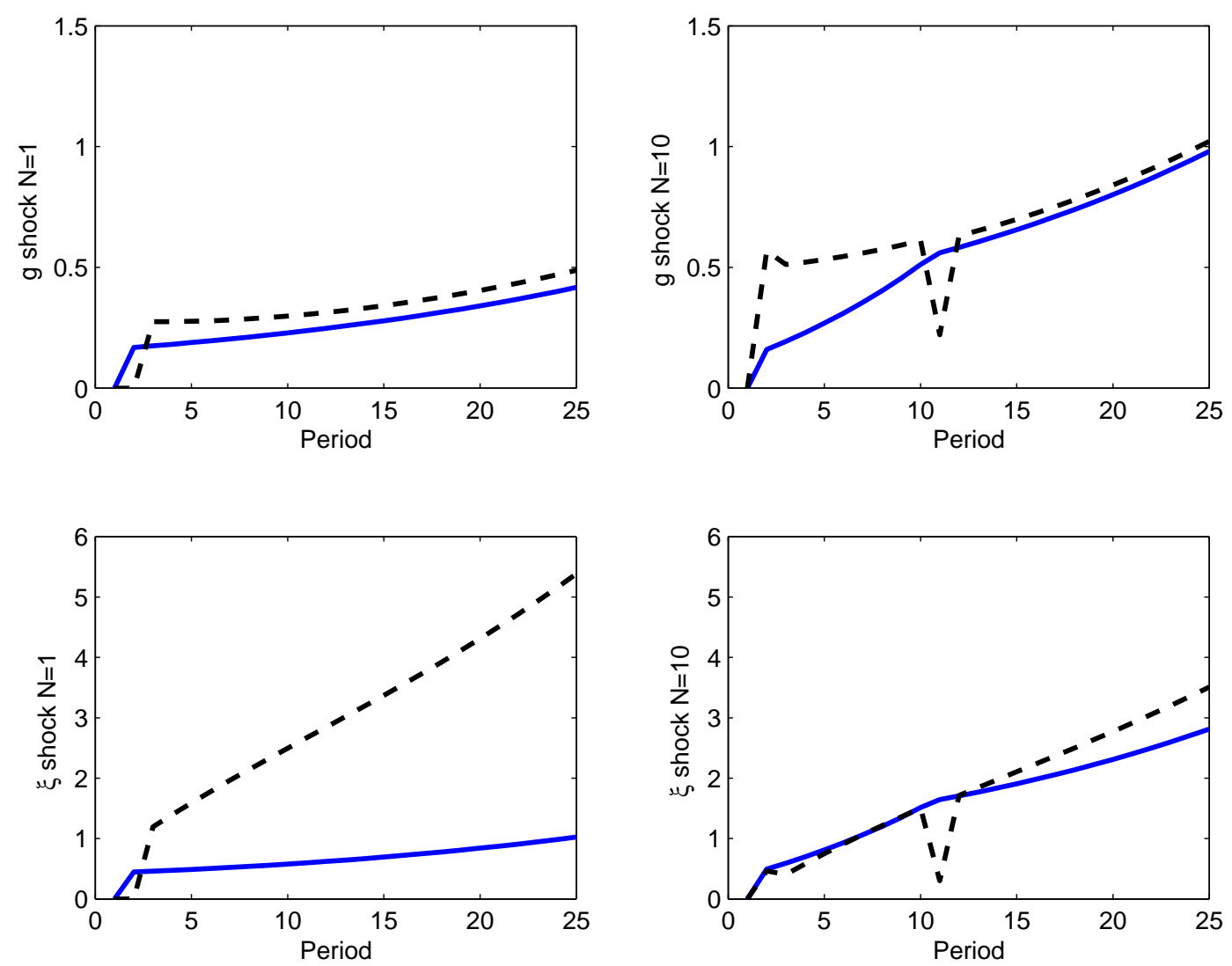

The top panels plot the decomposition after a spending shock for $N=1$ (left) and $N=10$ (right). The bottom panel shows the decomposition after the preference shock. The solid line illustrates the dynamics of the market value (in percentage changes relative to the actual market value) when we remove the influence of inflation. The dashed line illustrates the behavior of debt if inflation is the only variable that contributes to debt dynamics.

Figure 6: Debt Decomposition: Responses of the Market Value of Debt (High Initial Debt) 

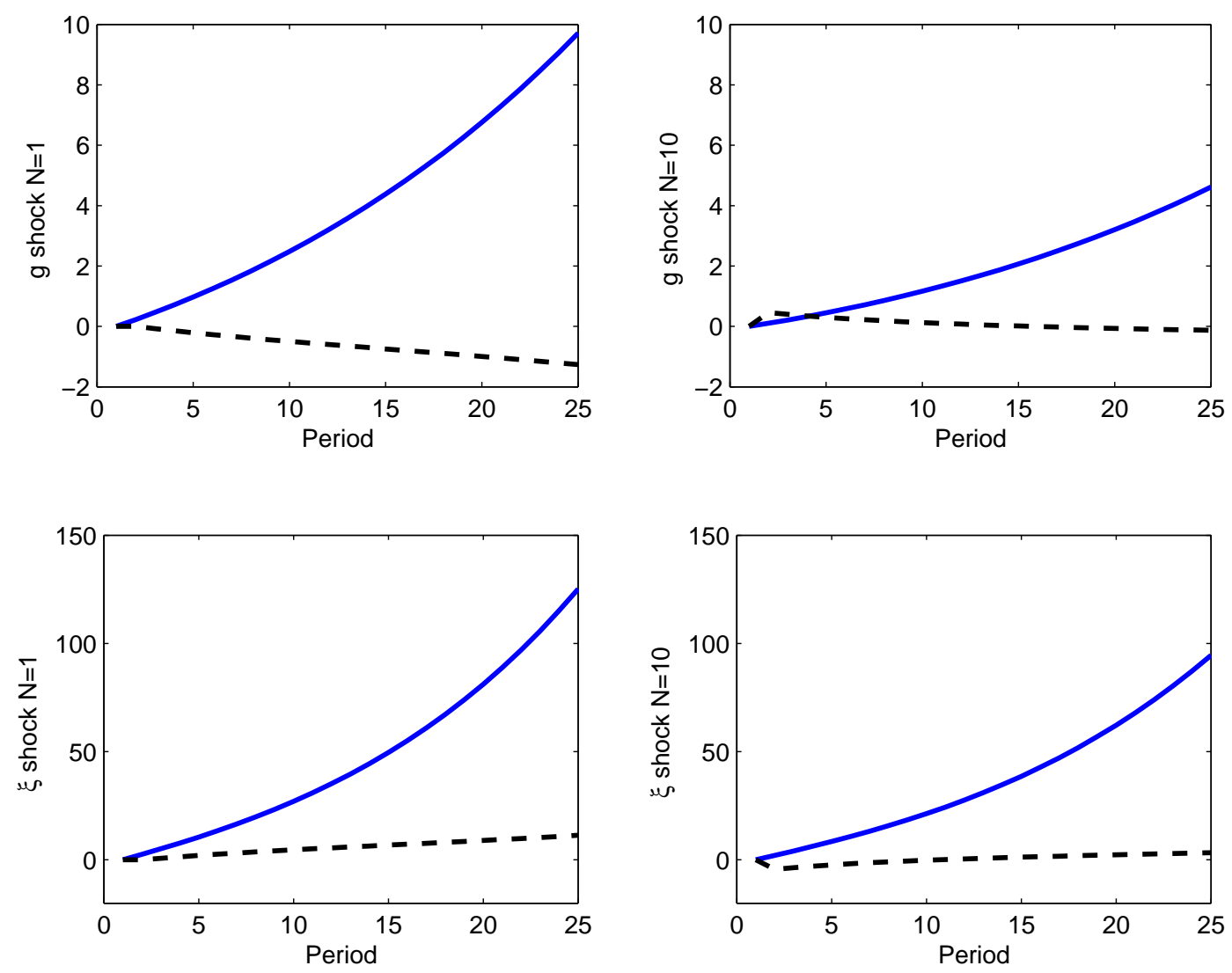

The top panels plot the decomposition after a spending shock for $N=1$ (left) and $N=10$ (right). The bottom panel shows the decomposition after the preference shock. The solid line illustrates the dynamics of the market value (in percentage changes relative to the actual market value) when we remove the influence of inflation. The dashed line illustrates the behavior of debt if inflation is the only variable that contributes to debt dynamics.

Figure 7: Debt Decomposition: Responses of the Market Value of Debt, Taylor Rule Model 

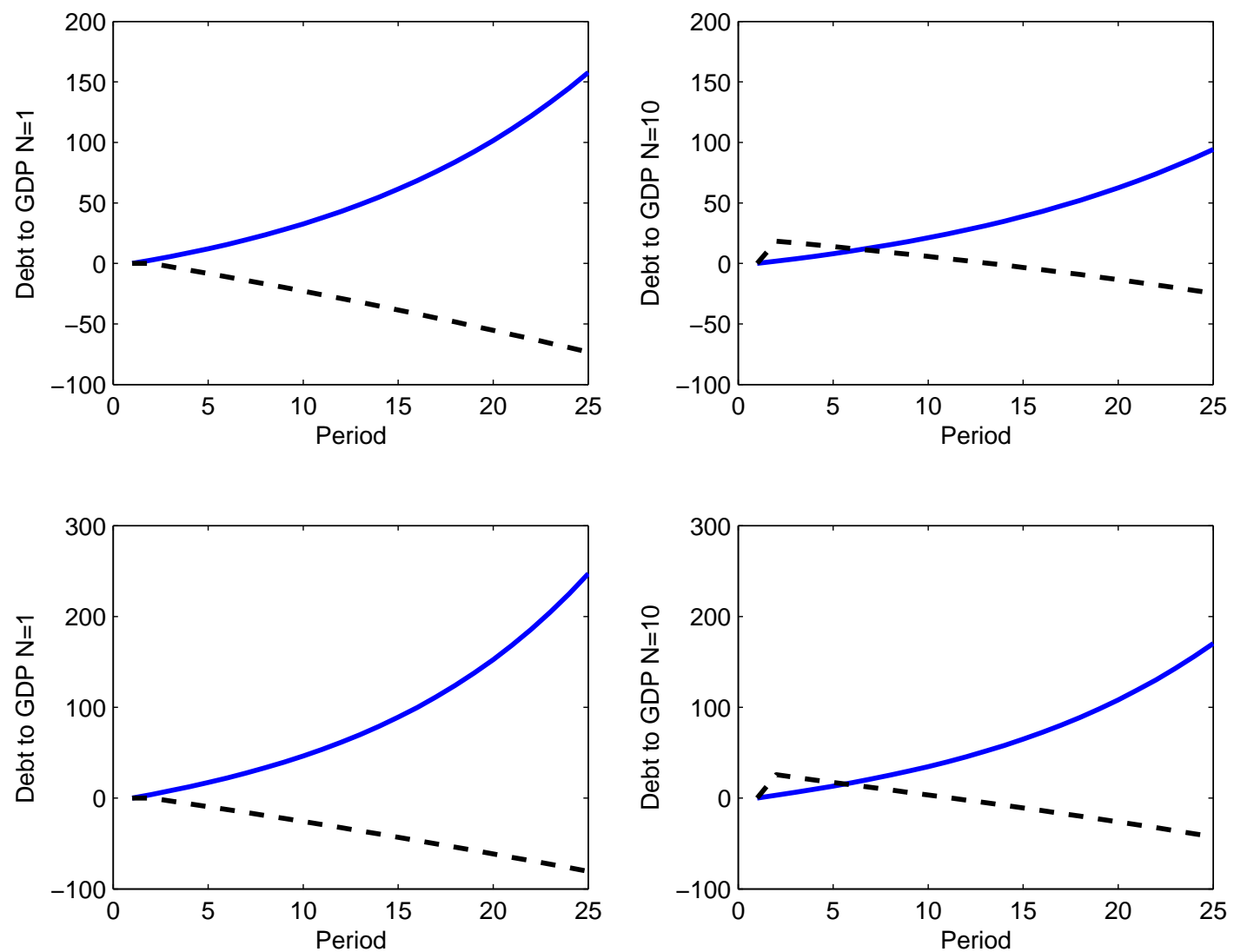

The top panels plot the decomposition after a spending shock for $N=1$ (left) and $N=10$ (right). The bottom panel shows the decomposition after the preference shock. The solid line illustrates the dynamics of the market value (in percentage changes relative to the actual market value) when we remove the influence of inflation. The dashed line illustrates the behavior of debt if inflation is the only variable that contributes to debt dynamics.

Figure 8: Debt Decomposition: Responses of the Market Value of Debt, Taylor Rule Model (High Initial Debt) 


\begin{tabular}{c|c|c|c|c}
\hline Model & $N=1$ & $N=5$ & $N=10$ & $N=20$ \\
\hline $\bar{b}^{N}$ & $33.0 \%$ & $31.9 \%$ & $49.0 \%$ & $62.7 \%$ \\
$\overline{M V}$ & $31.7 \%$ & $26.2 \%$ & $33.0 \%$ & $29.0 \%$ \\
$\sigma_{\pi}$ & $0.429 \%$ & $0.462 \%$ & $0.470 \%$ & $0.557 \%$ \\
$\operatorname{corr}\left(\pi, \pi_{t-1}\right)$ & 0.136 & 0.27 & 0.338 & 0.534 \\
$\sigma_{Y}$ & 0.0279 & 0.0283 & 0.0282 & 0.0283 \\
$\sigma_{\tau}$ & 0.0333 & 0.0354 & 0.0354 & 0.0352 \\
\hline
\end{tabular}

Notes: $\sigma_{x}$ is the standard deviation of variable $x$; $\operatorname{corr}(x, y)$ denotes the correlation between variables $x$ and $y$. Upper bars denote sample means. The market value of debt is constructed using the formula $M V_{t}=\beta^{N} E_{t} \frac{u_{c}\left(c_{t+N}, \xi_{t+N}\right)}{\Pi_{t+1}^{t+N} \pi_{j} u_{c}\left(c_{t}, \xi_{t}\right)} b_{t}^{N}$. The mean values of bonds and the market value of debt reported in the first and second rows are expressed relative to average output in our economy.

Table 1: Moments: Long samples

\begin{tabular}{ccccc}
\hline \hline Debt/GDP & $0 \%$ & $30 \%$ & $60 \%$ & $90 \%$ \\
\hline Model & \multicolumn{5}{c}{ Short Maturity $N=1$} \\
$\sigma_{\pi}$ & $0.44 \%$ & $0.42 \%$ & $0.45 \%$ & $0.53 \%$ \\
$\operatorname{corr}\left(\pi, \pi_{t-1}\right)$ & 0.195 & 0.163 & 0.133 & 0.087 \\
\hline Model & Long Maturity $N=10$ \\
$\sigma_{\pi}$ & $0.46 \%$ & $0.44 \%$ & $0.47 \%$ & $0.60 \%$ \\
$\operatorname{corr}\left(\pi, \pi_{t-1}\right)$ & 0.256 & 0.271 & 0.288 & 0.290 \\
\hline \hline
\end{tabular}

Notes: $\sigma_{x}$ is the standard deviation of variable $x ; \operatorname{corr}(x, y)$ denotes the correlation between variables $x$ and $y$. The top (bottom) panel corresponds to the short (long) bond economy.

Table 2: Moments: Short samples 


\begin{tabular}{l|c|c|c|c}
\hline Model & $N=1$ & $N=5$ & $N=10$ & $N=20$ \\
\hline \multirow{2}{*}{$\sigma_{\pi}$} & \multicolumn{4}{|c}{ Target Steady State Output } \\
$\operatorname{corr}\left(\pi, \pi_{t-1}\right)$ & $19.95 \%$ & $12.33 \%$ & $9.88 \%$ & $8.23 \%$ \\
$\sigma_{Y}$ & 0.937 & 0.939 & 0.938 & 0.941 \\
$\sigma_{\tau}$ & 0.0085 & 0.0060 & 0.0052 & 0.0046 \\
\hline \multirow{2}{*}{$\begin{array}{c}|c| \\
\sigma_{\pi}\end{array}$} & 0.0407 & 0.0702 & 0.0790 & 0.0869 \\
$\operatorname{corr}\left(\pi, \pi_{t-1}\right)$ & 0.942 & 0.938 & 0.939 & 0.941 \\
$\sigma_{Y}$ & 0.0259 & 0.0250 & 0.0249 & 0.0246 \\
$\sigma_{\tau}$ & 0.0268 & 0.0157 & 0.0119 & 0.0089 \\
\hline
\end{tabular}

Notes: $\sigma_{x}$ is the standard deviation of variable $x$; $\operatorname{corr}(x, y)$ denotes the correlation between variables $x$ and $y$. The top four rows correspond to the economy where the target output is the steady state output. The bottom panel corresponds to the model where the target is the complete market (efficient) output.

Table 3: Moments: Long samples Constrained Model

\begin{tabular}{cccc}
\hline Model & $N=5$ & $N=10$ & $N=20$ \\
\hline$\lambda_{s}$ & 0.0048 & 0.0083 & 0.0061 \\
$i^{N}$ & 0.0064 & 0.0041 & 0.0025 \\
$i^{N-1}$ & 0.0084 & 0.0047 & 0.0028 \\
\hline
\end{tabular}

Table 4: Euler Equation Errors

\begin{tabular}{c|cc|cc|cc}
\hline Model & $\lambda_{s}$ & $\lambda_{s, i m p l}$ & $p^{N}$ & $p_{i m p l}^{N}$ & $p^{N-1}$ & $p_{i m p l}^{N-1}$ \\
\hline $\begin{array}{c}N=5 \\
\text { ave }\end{array}$ & 0.513 & 0.512 & 0.816 & 0.815 & 0.850 & 0.849 \\
$\begin{array}{c}\sigma \\
N=10\end{array}$ & 0.082 & 0.081 & 0.016 & 0.019 & 0.014 & 0.016 \\
$\begin{array}{c}\text { ave } \\
\sigma\end{array}$ & 0.510 & 0.510 & 0.668 & 0.668 & 0.695 & 0.696 \\
$N=20$ & 0.084 & 0.083 & 0.018 & 0.020 & 0.017 & 0.020 \\
ave & 0.512 & 0.512 & 0.452 & 0.453 & 0.470 & 0.472 \\
$\sigma$ & 0.077 & 0.077 & 0.015 & 0.018 & 0.015 & 0.018 \\
\hline
\end{tabular}

Table 5: Euler Equation Errors actual and implied moments 


\begin{tabular}{c|cc|cc|cc|cc}
\hline Model & $c$ & $c_{i m p l}$ & $b^{N}$ & $b_{i m p l}^{N}$ & $\pi$ & $\pi_{i m p l}$ & $Y$ & $Y_{i m p l}$ \\
\hline$N=5$ & & & & & & & & \\
ave & 0.165 & 0.165 & 0.068 & 0.068 & 1.000 & 1.000 & 0.205 & 0.205 \\
$\quad \begin{array}{c}\sigma \\
N=10\end{array}$ & 0.030 & 0.028 & 0.057 & 0.056 & 0.005 & 0.005 & 0.030 & 0.028 \\
ave & 0.165 & 0.165 & 0.077 & 0.076 & 1.000 & 0.999 & 0.205 & 0.205 \\
$\sigma$ & 0.030 & 0.028 & 0.066 & 0.065 & 0.005 & 0.006 & 0.030 & 0.028 \\
$N=20$ & & & & & & & & \\
ave & 0.165 & 0.164 & 0.128 & 0.129 & 0.999 & 0.998 & 0.205 & 0.204 \\
$\sigma$ & 0.030 & 0.028 & 0.096 & 0.097 & 0.005 & 0.006 & 0.030 & 0.027 \\
\hline
\end{tabular}

Table 6: Euler Equation Errors actual and implied moments

\begin{tabular}{cccc}
\hline Model & $N=5$ & $N=10$ & $N=20$ \\
\hline$\lambda$ & -0.00000452 & -0.00001530 & -0.00002671 \\
$p^{N}$ & 0.00000828 & -0.00006826 & -0.00000649 \\
$p^{N-1}$ & 0.00000344 & -0.00004483 & -0.00003533 \\
\hline
\end{tabular}

Table 7: Simple Den Haan and Marcet Test 